\title{
Review-Cobalt Thin Films: Trends in Processing Technologies and Emerging Applications
}

\author{
Alain E. Kaloyeros, ${ }^{1}$ Youlin Pan, ${ }^{2}$ Jonathan Goff, ${ }^{2}$ and Barry Arkles ${ }^{2, z}$ \\ ${ }^{1}$ SUNY Polytechnic Institute, Albany, New York 12203, USA \\ ${ }^{2}$ Gelest, Inc., Morrisville, Pennsylvania 19067, USA
}

Cobalt metallic films are the subject of an ever-expanding academic and industrial interest for incorporation into a multitude of new technological applications. This report reviews the state-of-the art chemistry and deposition techniques for cobalt thin films, highlighting innovations in cobalt metal-organic chemical vapor deposition (MOCVD), plasma and thermal atomic layer deposition (ALD), as well as pulsed MOCVD technologies, and focusing on cobalt source precursors, thin and ultrathin film growth processes, and the resulting effects on film composition, resistivity and other pertinent properties.

(C) The Author(s) 2019. Published by ECS. This is an open access article distributed under the terms of the Creative Commons Attribution 4.0 License (CC BY, http://creativecommons.org/licenses/by/4.0/), which permits unrestricted reuse of the work in any medium, provided the original work is properly cited. [DOI: $10.1149 / 2.0051902 \mathrm{jss}$ ]

Manuscript submitted January 2, 2019; revised manuscript received February 4, 2019. Published February 27, 2019.

An increasing level of research and development $(\mathrm{R} \& \mathrm{D})$ activity is now focused on cobalt thin and ultrathin film structures, which have found myriad new applications across a variety of industrial sectors. ${ }^{1,2}$ This attraction to cobalt is driven by its appealing physical, mechanical and electrical properties. ${ }^{3,4}$ In particular, metallic cobalt films play a key role in the reliability of integrated circuitry (IC) devices, as metallic cobalt films' greater resistance to electromigration and lower tendency to undergo diffusion gives them a higher comparative stability relative to copper $(\mathrm{Cu})$ in environments that involve both elevated temperature and high current density induced stresses.

These salient properties have compelled consideration for a wealth of applications in IC systems, both in traditional architectures as well as novel systems associated with cobalt magnetic dipole moment, such as spintronic and giant magnetoresistance (GMR) devices ${ }^{5-10}$ IC device manufacturers recently reporting the use of cobalt in nanoscale metallization architectures include Intel, TSMC and Samsunghaving introduced it at the 10,14 and $16 \mathrm{~nm}$ nodes, respectively. ${ }^{11,12}$ In addition, cobalt's use as an actual conductor in nanoscale topographies is currently believed to be in limited production.

Further advantage for IC technologies includes the fact that cobalt (Co) thin films can act as seed layers for electroplated cobalt and undergo post-deposition conversion to binary element compounds such as cobalt silicide, cobalt sulfide, cobalt oxide and metallic alloys. For example, cobalt silicide $\left(\mathrm{CoSi}_{2}\right)$ conversion coatings ${ }^{13}$ are emerging as a viable replacement for titanium silicide in selfaligned silicide (salicide) applications due to wider silicidation window, which is consistent with the requirements for generating finer line geometries.

These commercial usages have spawned tremendous interest not only in optimizing and understanding Co film growth processes and resulting properties, but also in expanding their use in future IC products. Other uses of metallic cobalt and cobalt containing films (such as oxides, sulfides, silicides and nitrides) include magneto-optic recording media, ${ }^{14}$ data storage, ${ }^{15,16}$ sensor technologies,${ }^{15,17-19}$ catalysts for growing carbon nanotubes and self-aligned nanowires, ${ }^{15,18,19}$ reflective thin films for optical devices ${ }^{17}$ and, more broadly, as antibacterial, ${ }^{18,19}$ decorative, protective ${ }^{17}$ and wear-resistant coatings. ${ }^{20}$

Given cobalt's increasing potential to continue enabling exciting innovations across numerous industrial sectors, this article presents an overview of recent advancements in Co vapor phase processing techniques and their impact on film physical, chemical and electrical properties. While there is a broad literature on liquid phase deposition (electroplating) for cobalt, cobalt oxide and cobalt sulfide, this focuses predominantly on industrial finishes, with a smaller representation in photovoltaic \& storage devices. ${ }^{21-23}$ Only a very limited number of recent reports have been published on electroplating

${ }^{\mathrm{z}}$ E-mail: executiveoffice@gelest.com of Co for IC applications. ${ }^{24,25}$ Similarly, a large literature describes the use of non-metallic cobalt films in the hydrothermal conversion of cobalt salts. Although examples of these methods are included in this review when scientifically and technologically relevant, ${ }^{26}$ the vast majority of recent $R \& D$ efforts have centered on the growth of Co thin films through vapor phase deposition techniques. Accordingly, this article will primarily summarize and discuss the most recent work in such techniques - namely: thermal metal-organic chemical vapor deposition (MOCVD) and pulsed thermal MOCVD, as well as thermal, plasma and area-selective atomic layer deposition (ALD).

It is worth noting that the literature provides a complex representation of the thermal, chemical, electrical, compositional and morphological characteristics of Co thin films. This complexity is due to the fact that, in many cases, film properties are reported for the specific deposition process used to grow the Co thin films, while associated film morphologies, compositions and impurity levels are often neither comprehensively defined nor thoroughly reported. This review therefore focuses on specific film properties and performance as they relate to specific Co processing technologies, with a particular emphasis on IC metallization. Given the rapid evolution of cobalt deposition technologies, the majority of reports summarized and discussed here were published within the last ten years; however, earlier work is referenced and reviewed as needed in order to place more recent work in the appropriate context.

\section{Fundamental Properties of Cobalt}

Any review of the latest accomplishments in Co processing technologies must begin with a summary of metallic cobalt's fundamental properties. There are two primary Co crystalline configurations of metallic cobalt: face-centered-cubic (fcc) and hexagonal close packed (hcp). ${ }^{27,28}$ However, there is currently no data compilation that comprehensively describes the properties of Co thin films. Co thin film data in the literature is often incompletely characterized in terms of crystallinity, domain size and other morphological characteristics; this is also true in regards to compositional aspects, since the incorporation into Co thin films of low atomic percentages of other elements-such as $\mathrm{C}, \mathrm{O}$ and $\mathrm{H}$ (as a result of the deposition process), as well as other elements such as $\mathrm{Si}$ and $\mathrm{Cu}$ (as a result of inter-diffusion with the substrate during deposition) - is not always considered or fully reported.

Table I displays nominal properties for cobalt and selected cobalt binary compounds associated with semiconductor applications. The data presented should be viewed by the reader as guide, but should not be taken as specific to any particular Co thin film formed by any of the techniques discussed herein. The information is meant to represent relevant, albeit not absolute, properties of Co films obtained at temperatures in the range of $20^{\circ}-100^{\circ} \mathrm{C}$, with the obvious 
Table I. Overview of Pertinent Properties of Cobalt.

\begin{tabular}{|c|c|c|c|c|c|c|}
\hline & \multicolumn{3}{|c|}{ Elemental Cobalt } & & & \\
\hline & \multirow[t]{2}{*}{ Bulk } & \multicolumn{2}{|c|}{ Thin Film } & \multicolumn{3}{|c|}{ Binary Cobalt Systems } \\
\hline & & MOCVD & ALD & Cobalt Disilicide & Cobalt Sulfide & Cobalt Oxide \\
\hline Formula & $\mathrm{Co}$ & \multicolumn{2}{|l|}{ Co } & $\mathrm{CoSi}_{2}$ & $\operatorname{CoS}$ & $\mathrm{CoO}$ \\
\hline Atomic/Molecular Weight & 58.933 & \multicolumn{2}{|l|}{58.933} & 115.10 & 91.00 & 74.93 \\
\hline \multicolumn{7}{|l|}{ Thermal } \\
\hline Transformation temp, ${ }^{\circ} \mathrm{C}$ (hcp to fcc) & $417^{\circ}$ & & & & & \\
\hline$\Delta \mathrm{H}$ transformation $\mathrm{J} / \mathrm{g}$ & 251 & & & & & \\
\hline Melt Point & $1493^{\circ}$ & & & $1277^{\circ}$ & $1182^{\circ}$ & $1800^{\circ}$ \\
\hline$\Delta$ heat of fusion $\mathrm{J} / \mathrm{g}$ & 259.4 & & & & & \\
\hline Boiling Point, ${ }^{\circ} \mathrm{C}$ & $3100^{\circ}$ & & & & & \\
\hline$\Delta$ heat of vaporization $\mathrm{J} / \mathrm{g}$ & 6276 & & & & & \\
\hline Specific heat $\mathrm{J} / \mathrm{g} \cdot{ }^{\circ} \mathrm{C}$ & 0.442 & & & & & \\
\hline Coefficient of Thermal Expansion, $\mathrm{x} 10^{-6},{ }^{\circ} \mathrm{C}^{-1}$ & & & & $\sim 10$ & & \\
\hline hcp, $25^{\circ} \mathrm{C}$ & 12.5 & & & & & \\
\hline fcc, $417^{\circ} \mathrm{C}$ & 14.2 & & & & & \\
\hline Curie Temp, ${ }^{\circ} \mathrm{C}$ & $1121^{\circ}$ & & & & & \\
\hline \multicolumn{7}{|l|}{ Electrical } \\
\hline Resistivity $\left(20^{\circ} \mathrm{C}\right), \mu \Omega \cdot \mathrm{cm}$ & 6.2 & $8.5^{3} 17^{* 12}$ & $23^{* 23}$ & $10-25$ & $2000-3500$ & $1.1 \times 10^{5}$ \\
\hline Dielectric Constant & & & & & 3.241 & $12.9^{*}$ \\
\hline Electrochemical Potential (EMF-aqueous), V & $0.277(+2)$ & & & & & \\
\hline \multicolumn{7}{|l|}{ Magnetic } \\
\hline Permeability $\mu$ : initial; $\max$ & $68 ; 245$ & & & & & \\
\hline Residual induction, $\mathrm{T}^{\mathrm{c}}$ & 0.490 & & & & & \\
\hline Coercive force, $\mathrm{A} / \mathrm{m}$ & 708 & & & & & \\
\hline \multicolumn{7}{|l|}{ Mechanical } \\
\hline Youngs Modulus $\left(20^{\circ} \mathrm{C}\right), \mathrm{GPa}$ & 211 & & & & & \\
\hline Tensile Strength (annealed), MPa & 588 & & & & & \\
\hline Shear modulus, GPa & 82.6 & & & & & \\
\hline Poisson's Ratio & 0.32 & & & & & \\
\hline \multicolumn{7}{|l|}{ Optical } \\
\hline Refractive index, $589 \mathrm{~nm}$ & 2.142 & & & 3.094 & $\sim 2.5$ & 2.33 \\
\hline Band gap, eV & & & & & $1.35-1.6$ & 2.4 \\
\hline \multicolumn{7}{|l|}{ Other } \\
\hline Diffusion Rate in $\mathrm{Si}, \mathrm{cm}^{2} / \mathrm{s}$ & $10^{-6}-10^{-4}$ & & & & & \\
\hline Activation Energy (eV) (for diffusion in $\mathrm{Si}$ ) & 2.8 & & & & & \\
\hline
\end{tabular}

exception of thermal properties, and offers the reader a foundation for the study and examination of Co film properties as reported in the literature.

\section{Overview of Cobalt Thin Film Vapor Phase Deposition Techniques}

A cursory reading of the literature in this area quickly reveals both inconsistencies in precursor naming and a lack of universally accepted chemical acronyms. For the most part, the compound name in the primary reference has been retained in this review. However, in order to provide consistency for the reader, we have assigned an identification number to any precursor mentioned more than once for which a discrete chemical structure has been reported, as outlined in Table II. Within the text of this review, the identification numbers listed in Table II appear next to the precursor name used, and track to Chemical Abstract Systems (CAS) registration numbers. Table III presents a summary of recent MOCVD and ALD Co modeling and mechanistic studies, ${ }^{5-7}$ while Table IV contains a synopsis of recent thermal MOCVD Co reports; ${ }^{8-10,14-19,29-34}$ Table V provides summaries of recent pulsed thermal MOCVD and plasma and thermal ALD studies, ${ }^{20,26,35-54}$ and Table VI gives an outline of recent area-selective ALD work. ${ }^{26,51,55-66}$

As in many material systems, the evolution in Co processing protocols has proceeded from MOCVD-based to ALD-based technologies, a trend driven by the need for highly conformal ultra-thin Co films with well-defined composition and characteristics to be included in the reduced geometries and features of future devices, led by the IC and solar cell industries.

Thermal Co MOCVD is characterized by substrate surface driven reactions capable of yielding improved step coverage in aggressive device structures. Reactants, including a Co source precursor, are usually transported simultaneously in the gas phase to the substrate surface. ${ }^{8-10}$ The reactants then adsorb onto the substrate surface, with subsequent surface diffusion and desorption of some reactants or reactant species. Surface reactions follow, with film nucleation and 


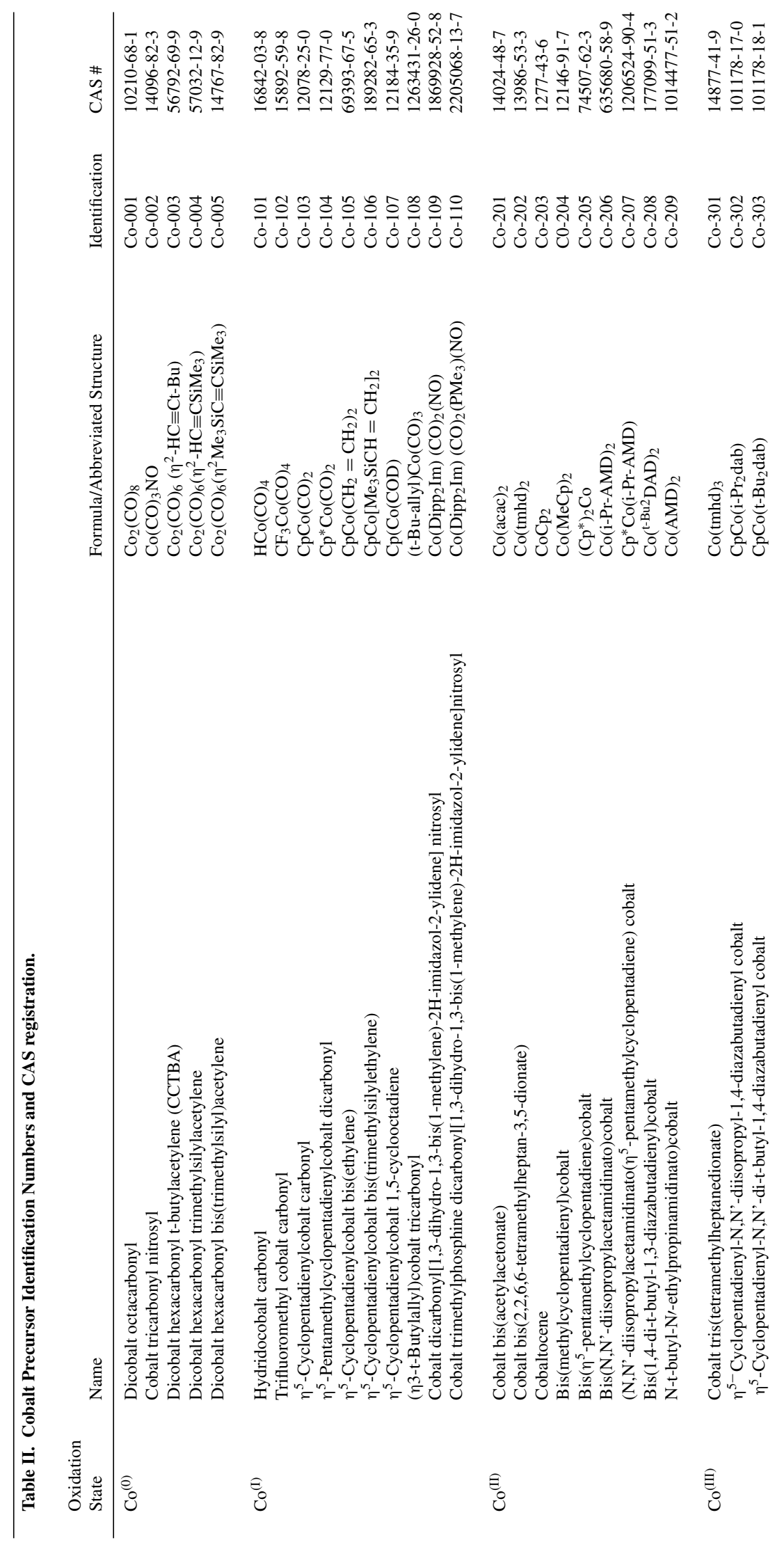




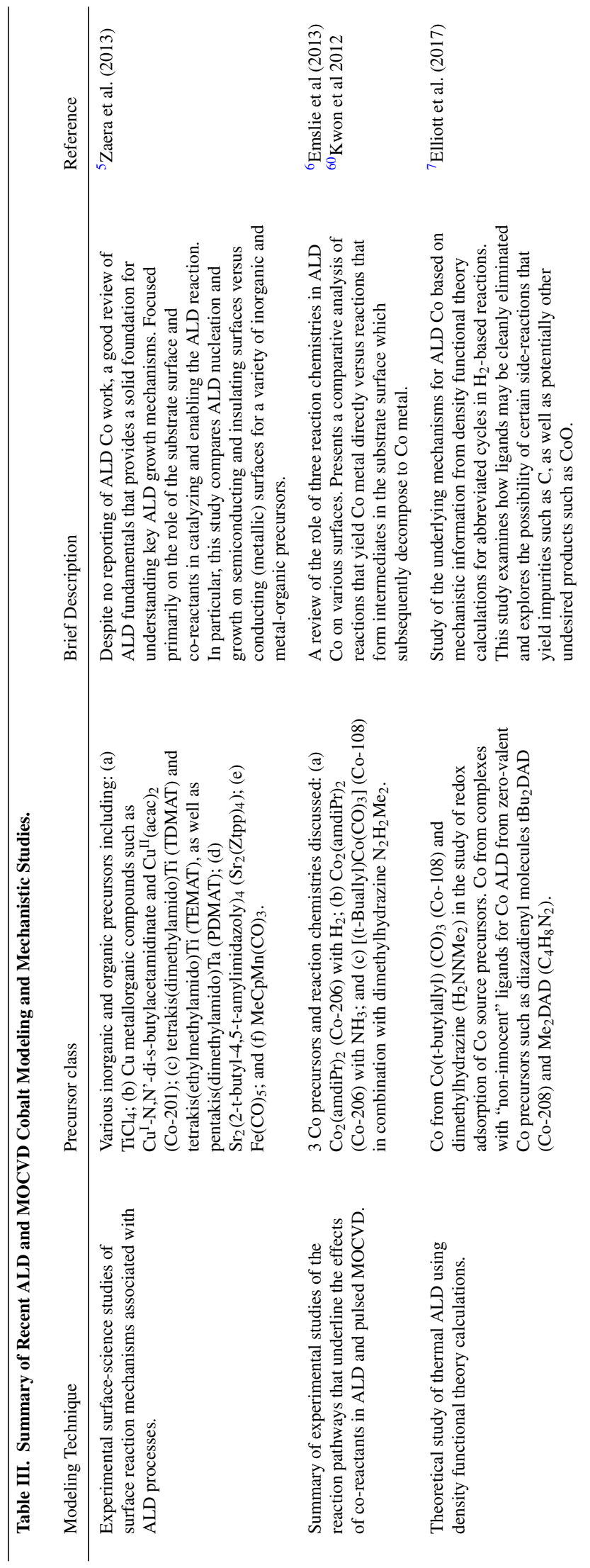




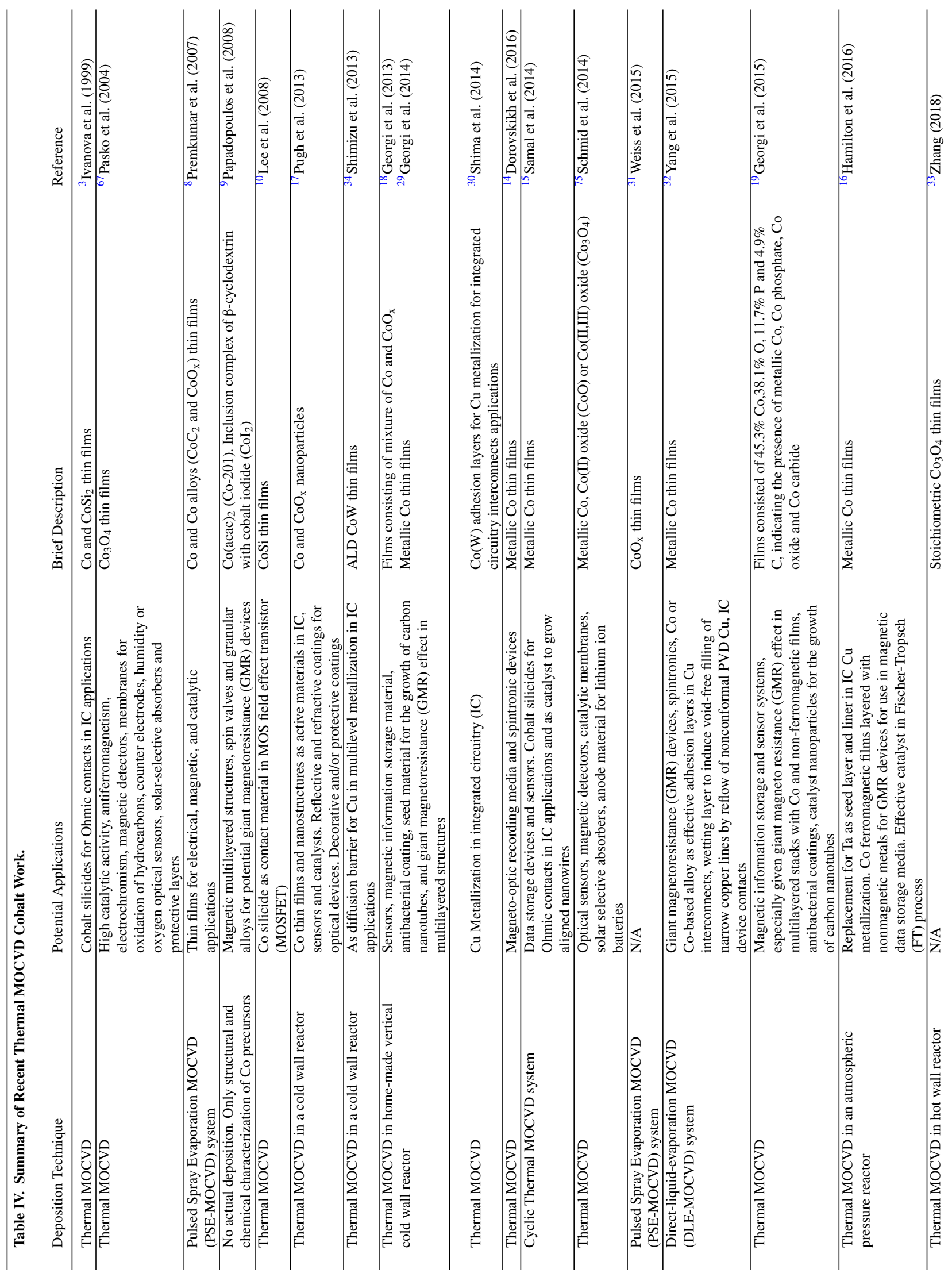




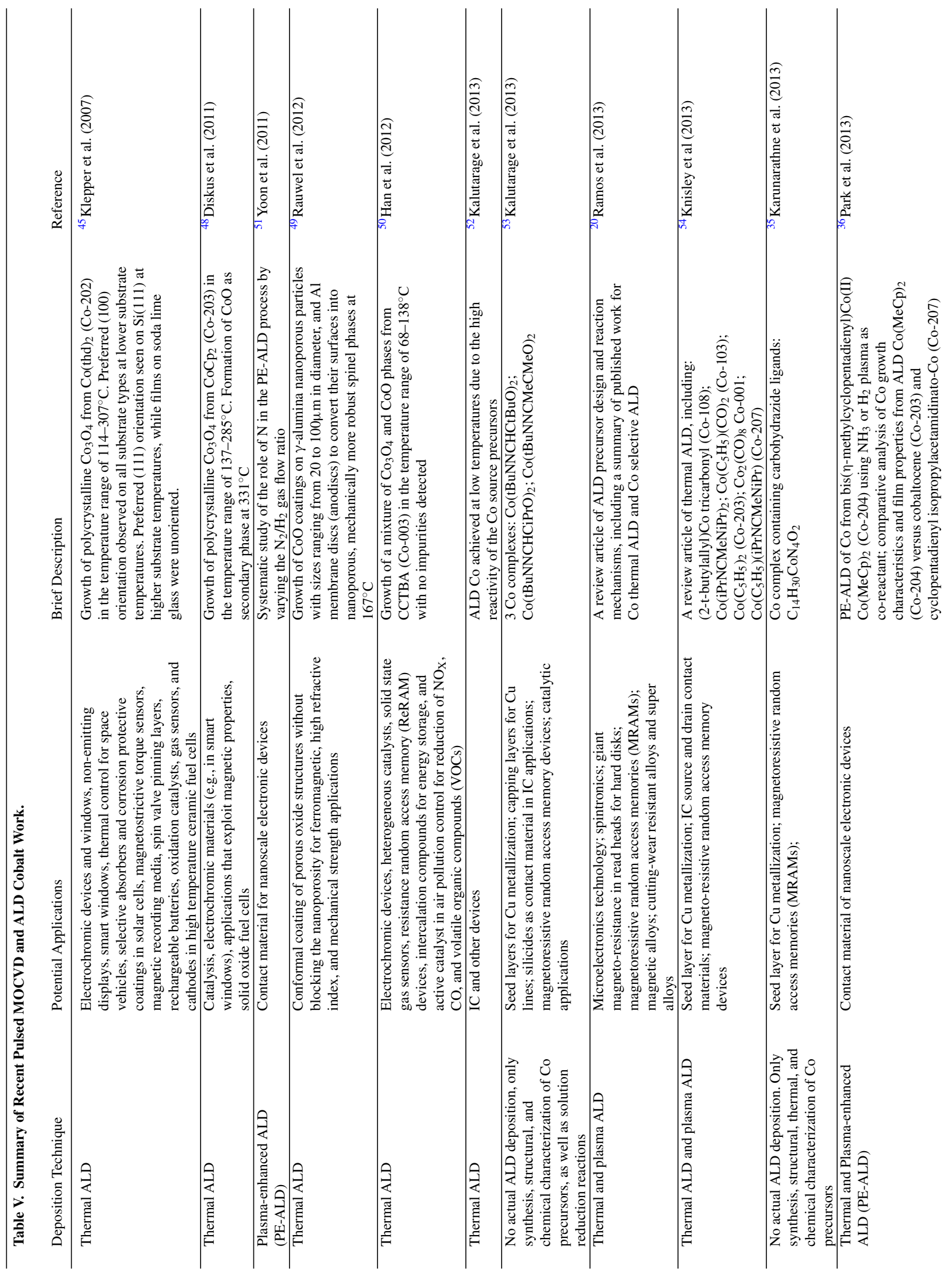




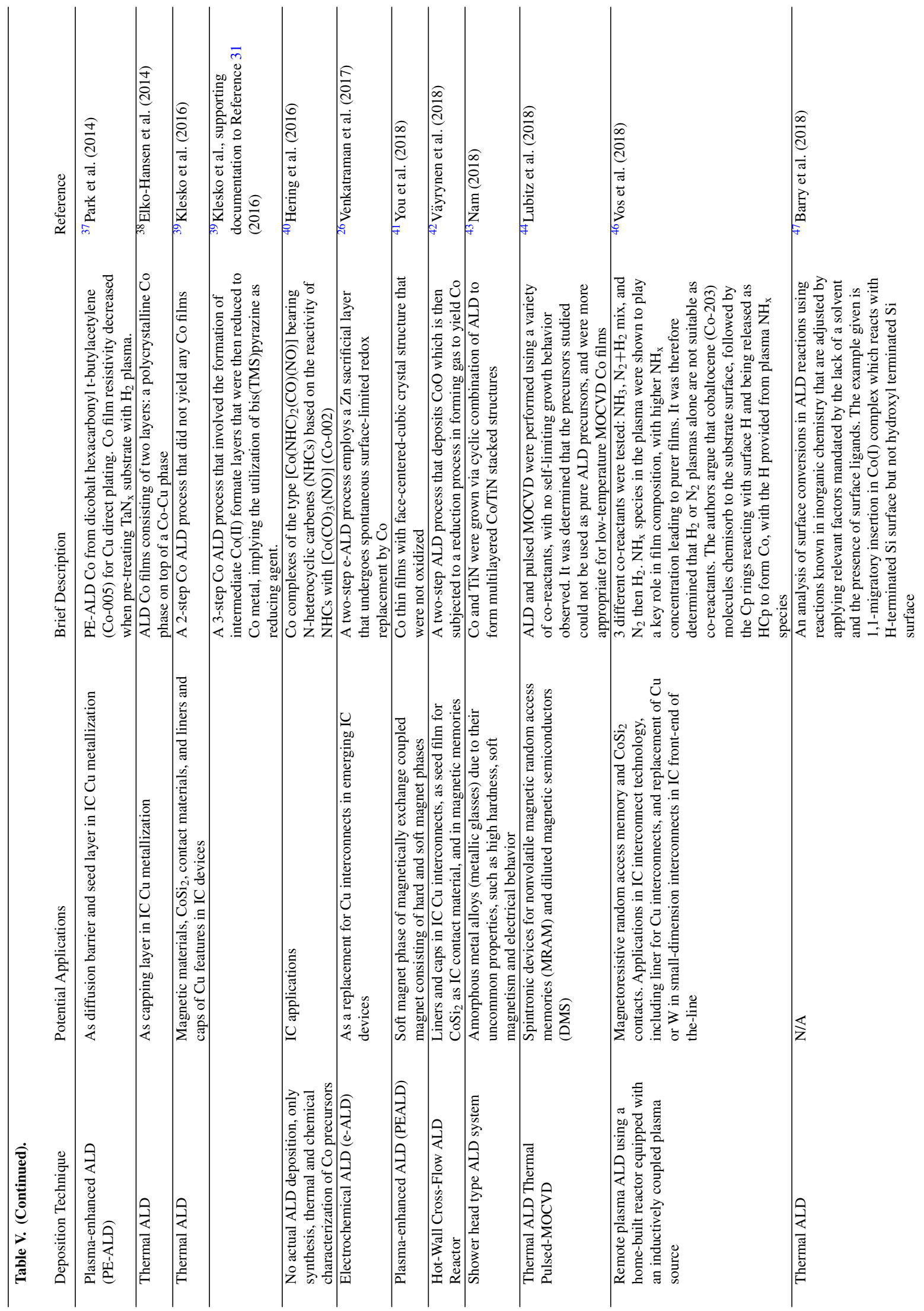




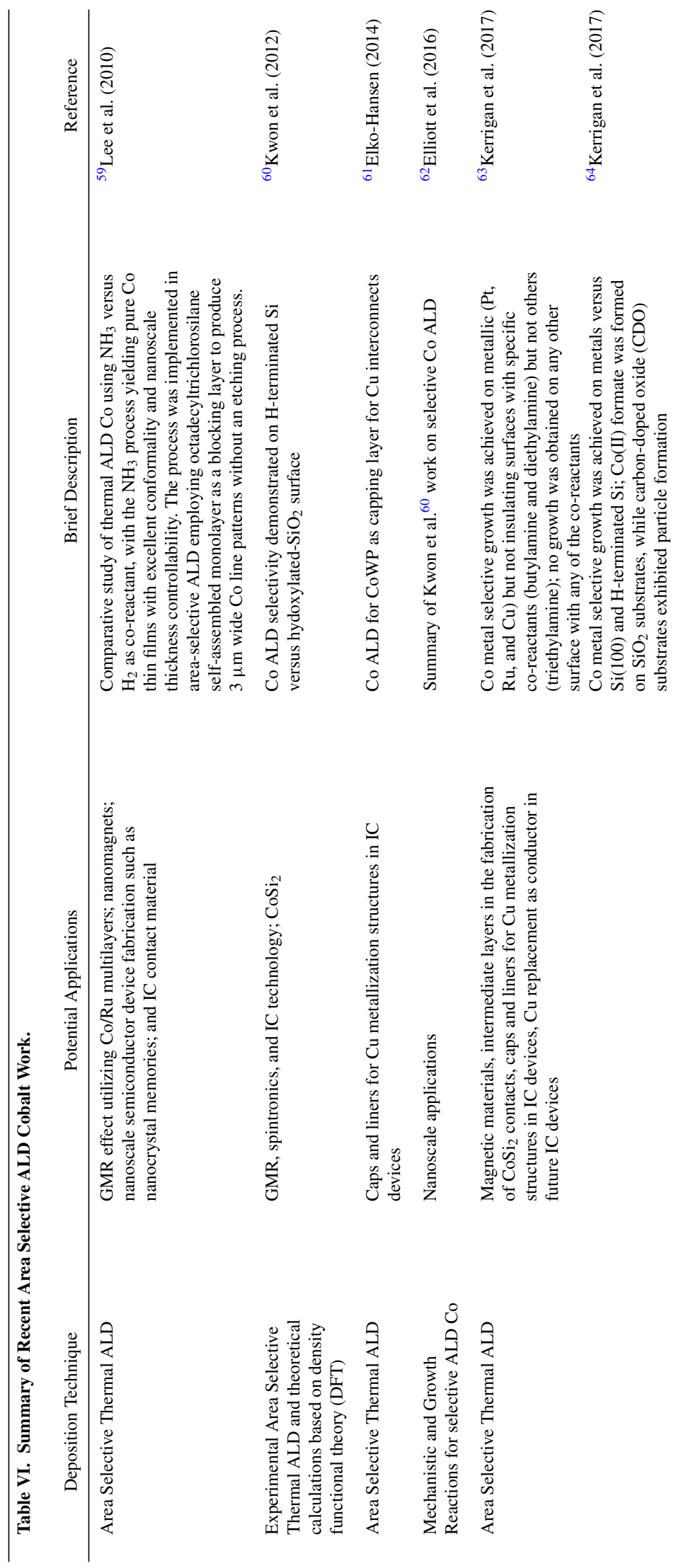


growth occurring either in island mode, layer-by-layer (step) mode, or a combination of modes. Concomitant with or subsequent to adsorption, volatile reaction byproducts are released from the substrate surface. Substrate temperature plays a pivotal role in the deposition process: ${ }^{17}$ increased substrate temperature leads to longer surface diffusion distances, thus extending surface reaction times and potentially producing enhanced step coverage and reduced contaminant incorporation. However, Co film growth in thermal MOCVD proceeds as isolated islands or disconnected layers until a specific thickness is achieved which enables the islands or layers to connect and establish a continuous film. ${ }^{15}$ Because this characteristic is not conducive to the formation of extremely thin coherent layers, MOCVD Co is of limited utility in nanoscale device features. An additional challenge in MOCVD Co is that of achieving tight control of surface reactions in order to precisely control the thickness of extremely thin films by minimizing film growth rates.

Thermal Co ALD is categorized by: (1) the introduction of the Co source precursor and co-reactant in sequential rather than simultaneous stages, with intervening purge steps to ensure that the co-reactants never cross paths in the reaction zone and that no reactions occur except on the substrate surface; and (2) Co film growth proceeding through self-limiting surface reactions that ensure precise control of film thickness and conformality with atomic level accuracy. ${ }^{20,51-53}$ These characteristics suggest the realization of excellent film conformality in extremely aggressive device topographies. The addition of plasma to one of the co-reactants (e.g., $\mathrm{H}_{2}$ or $\mathrm{NH}_{3}$ ) has also been shown to enhance the ALD reaction and increase film growth rates by creating a higher concentration of active co-reactant radicals. Furthermore, the use of plasma to perform surface treatment between various ALD reaction steps leads to higher surface adsorption of Co precursor species by maximizing the concentration of active surface sites and decreasing reaction activation energy, thereby leading to lower deposition temperatures. ${ }^{36,51,54}$

ALD exhibits a number of attractive features..$^{26,37-41}$ In addition to enabling excellent conformality in nanoscale device topographies and feature sizes, ALD tends to grow particle and pin-hole free films while also providing excellent management of film thickness down to a few atoms. Another emerging advantage of thermal Co ALD is its ability to enable or prevent area-specific or area-selective film growth, in what is commonly referred to as area-selective ALD. ${ }^{59-64}$ Customized complexes (precursors) and surface assemblies or configurations can be made to react in a tightly controlled fashion so as to catalyze or inhibit Co deposition on specific areas of the underlying substrate surface, resulting in Co film formation only on the desired regions of the substrate. However, current ALD technologies suffer from high surface roughness and very limited growth rates (and thus low manufacturing throughput).

Reports have recently emerged on the development and application of pulsed Co MOCVD, ${ }^{6,20,44}$ the most widely accepted definition of which describes it as equivalent to thermal ALD, except that the process is performed at a substrate temperature leading to partial or complete decomposition of the pulsed Co precursor upon engagement with the substrate during every exposure cycle, rather than being limited to a simple physi- or chemi-sorption reaction. The co-reactant is subsequently introduced to complete the decomposition reaction and/or remove the reaction byproducts, ensuring a clean Co film. Pulsed MOCVD can also be defined as equivalent to thermal MOCVD, except that the co-reactants are pulsed simultaneously into the reaction zone.

A synopsis of Co source chemistries is presented below, with particular attention given to the potential role of Co oxidation state in driving the chemical properties and associated decomposition pathways of the corresponding Co complexes. To this end, Table X outlines the Co-, C- and $\mathrm{N}$ - bond dissociation energies for appropriate $\mathrm{Co}$ source chemistries, while Tables XI displays pertinent properties of the recently considered thermal MOCVD, pulsed thermal MOCVD, and thermal, plasma and area-selective ALD. Finally, key processing parameters and major findings are presented in Tables VIII, IX and X for thermal MOCVD, pulsed thermal MOCVD, and thermal, plasma and area-selective ALD, respectively, which are analyzed in detail in the relevant sections.

\section{Modeling and Mechanistic Studies}

Tables III presents a synopsis of several MOCVD and ALD Co theoretical and experimental modeling and mechanistic studies that shed light on the role of substrate surface and co-reactant chemistry in the adsorption and decomposition pathways of Co precursors and resulting film morphology, composition and properties.

Zaera et al. ${ }^{5}$ review the underlying mechanisms in thermal ALD and, although no ALD Co work is specifically discussed, present principles that are highly relevant to the subject of this review. In particular, the authors compare the role of semiconducting and insulating surfaces versus conducting surfaces in the precursor adsorption and decomposition process. They argue that precursor-substrate interactions are quite confined on semiconducting and insulating surfaces, where the electronic density is localized, involving specific atoms on the surface. In contrast, more complex precursor-substrate interactions are observed on metallic surfaces, where electronic density tends to be delocalized. In either case, however, precursor adsorption, decomposition and film growth appear to be initiated by specific reactive sites or lattice defects (nucleation centers) on the substrate surface. In the case of oxide substrates, for example, these reactive surface sites tend to be hydroxyl groups, with $\mathrm{OH}$ groups displacing precursor ligands and bonding through oxygen atoms to the remaining precursor structure. This coordination could take place with the $\mathrm{H}$ atom in the hydroxyl group being transferred to the displaced ligands, either concurrently, or subsequently to their removal. The degree of reactivity of these nucleation centers toward the ALD precursors could also be the reason for the ALD incubation delay or induction period that are reported during the first few cycles of the deposition process.

The review by Emslie et al. ${ }^{6}$ highlights the target requirements for the different classes of co-reactants used for metal ALD or pulsed MOCVD, and discusses the reaction pathways known or proposed to be involved in the corresponding ALD or pulsed MOCVD process. The authors argue that reactants must: (i) be sufficiently volatile to allow low-temperature ALD or pulsed MOCVD; (ii) have adequately high thermal stability to allow transport and delivery into the reaction zone while maintaining integrity; (iii) display reasonable reactivity with Co source precursor to enable ALD at substrate temperatures below the onset of MOCVD, and yield only volatile byproducts; (iv) have the ability to catalyze precursor reactions with substrate and Co film growth on both the initial substrate surface and the growing Co film. To this end, they emphasized two reports that analyzed and compared the role of ammonia $\left(\mathrm{NH}_{3}\right.$ ) versus dimethylhydrazine $\left(\mathrm{N}_{2} \mathrm{H}_{2} \mathrm{Me}_{2}\right)$ in the ALD and pulsed MOCVD growth of $\mathrm{Co}$ ( (i) $\mathrm{Co}_{2}\left(\mathrm{amd}^{\mathrm{iPr}}\right)_{2}(\mathrm{Co}-206)$ with $\mathrm{NH}_{3}$ on $\mathrm{H}$-terminated $\mathrm{Si}$ or $\mathrm{SiO}_{2}$ to grow Co metal at $350^{\circ} \mathrm{C}$, in which the reaction appears to proceed through the formation of $\mathrm{CoN}$ as an intermediate which subsequently decomposes to Co at approximately $300^{\circ} \mathrm{C}$ (via $\mathrm{Co}_{2} \mathrm{~N}$ and $\mathrm{Co}_{3} \mathrm{~N}$ ); (ii) t-Bu-allyl) $\mathrm{Co}(\mathrm{CO})_{3}(\mathrm{Co}-108)$ with dimethylhydrazine $\left(\mathrm{N}_{2} \mathrm{H}_{2} \mathrm{Me}_{2}\right)$ on $\mathrm{H}$-terminated $\mathrm{Si}$ to grow $\mathrm{Co}$ at $140^{\circ} \mathrm{C},{ }^{60}$ in which the low temperature precludes the formation of $\mathrm{CoN}$ as an intermediate, indicating that the reaction proceeds directly to the formation of Co metal.

Elliott et al. ${ }^{7}$ performed a multi-phase theoretical study of the underlying mechanisms in ALD Co from t-Bu-allyl $) \mathrm{Co}(\mathrm{CO})_{3}(\mathrm{Co}-$ 108) and zero-valent Co complexes containing "non-innocent" ligands such as the diazadienyl molecules $\mathrm{tBu}_{2} \mathrm{DAD}(\mathrm{Co}-208)$ and $\mathrm{Me}_{2} \mathrm{DAD}\left(\mathrm{C}_{4} \mathrm{H}_{8} \mathrm{~N}_{2}\right)$. Employing mechanistic information from density functional theory calculations for shortened cycles of precursor interactions with co-reactants such as $\mathrm{H}_{2}$, the authors investigated how ligands can be cleanly eliminated to yield pure $\mathrm{Co}$, as well as what effects side-reactions could have on the incorporation of impurities (such as C) and other unwanted products (such as $\mathrm{CoO}$ ).

Phase I of this study explored the adsorption of t-Bu-allyl $) \mathrm{Co}(\mathrm{CO})_{3}$ (Co-108) and selective deposition on H-terminated $\mathrm{Si}$ versus $\mathrm{OH}-$ 


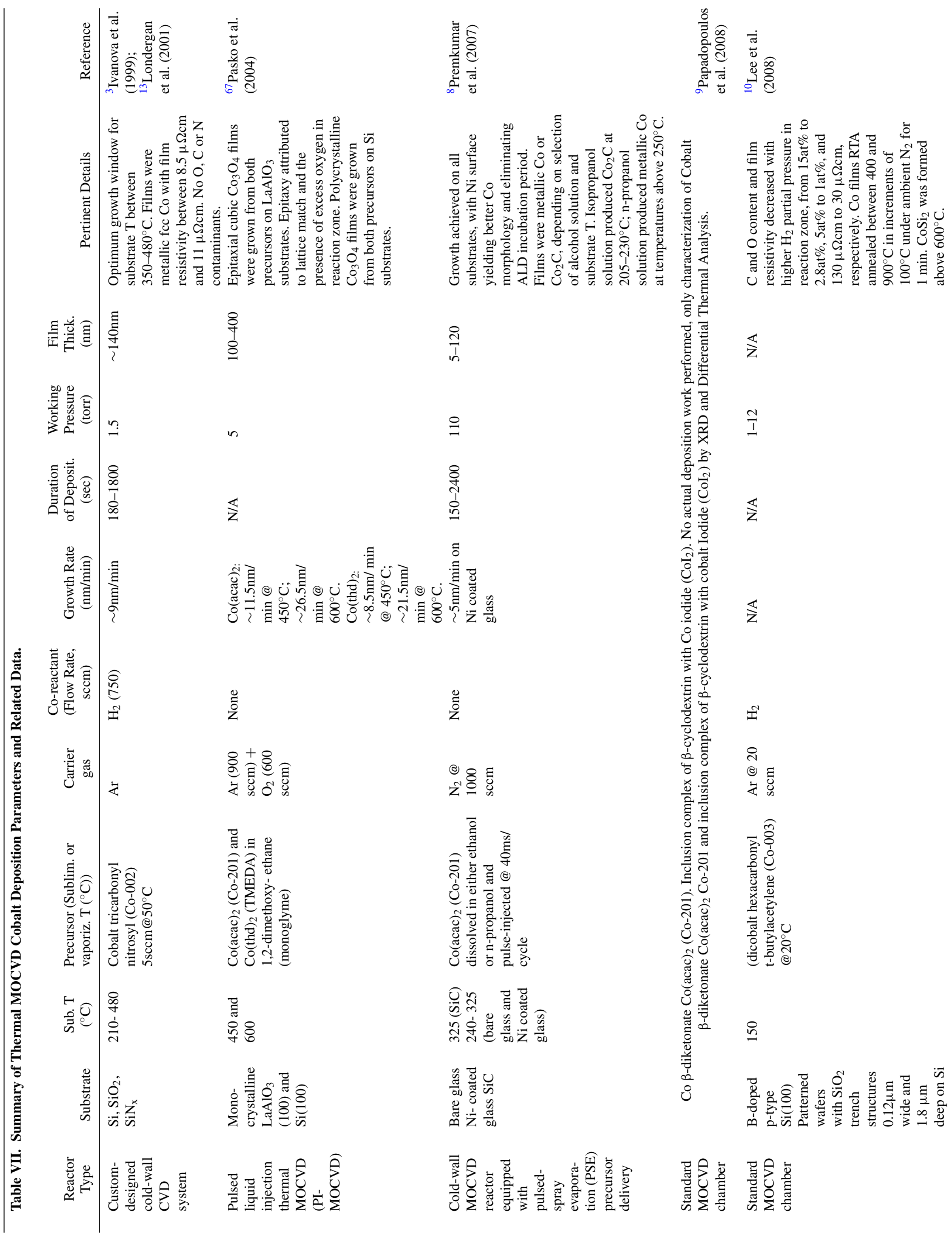




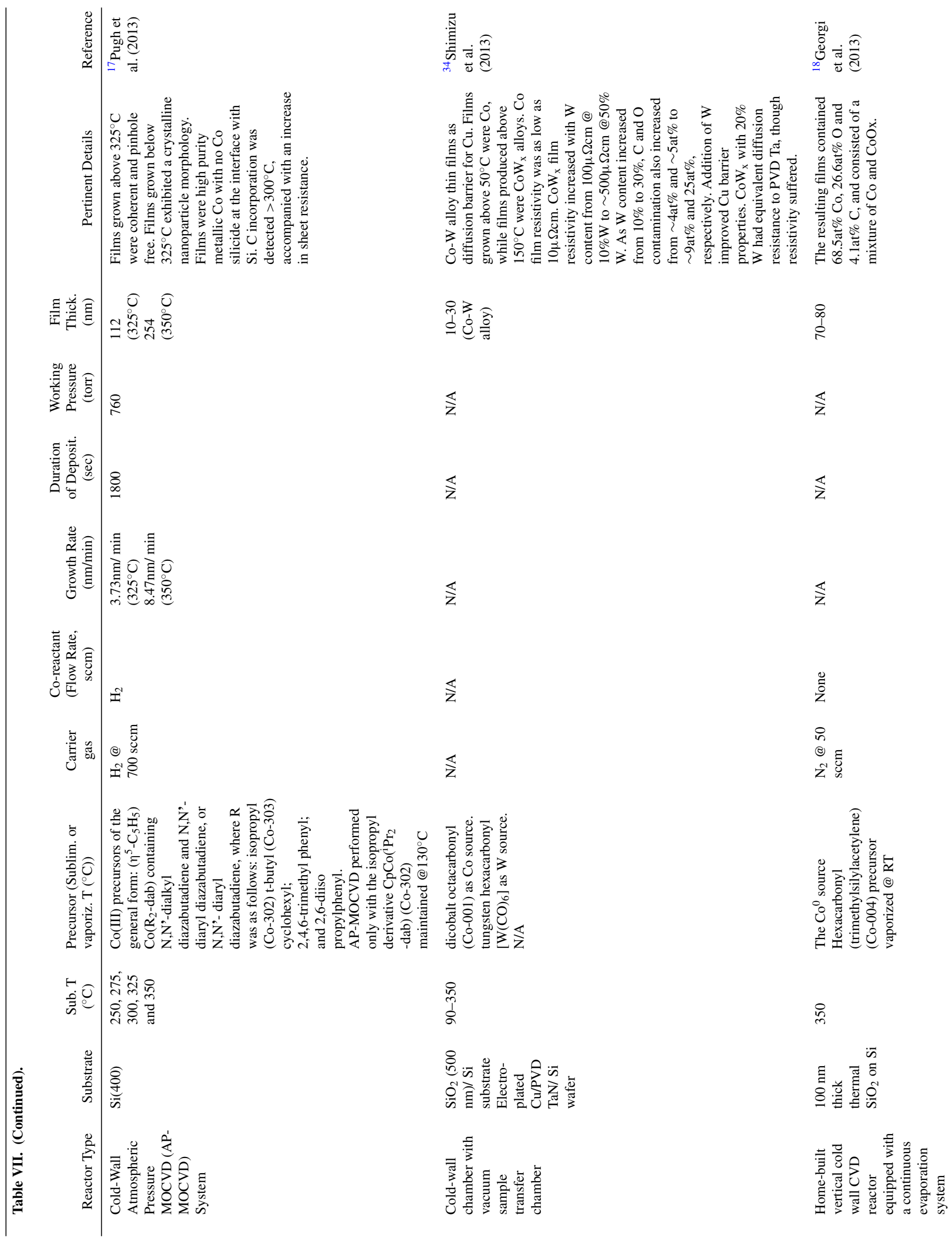




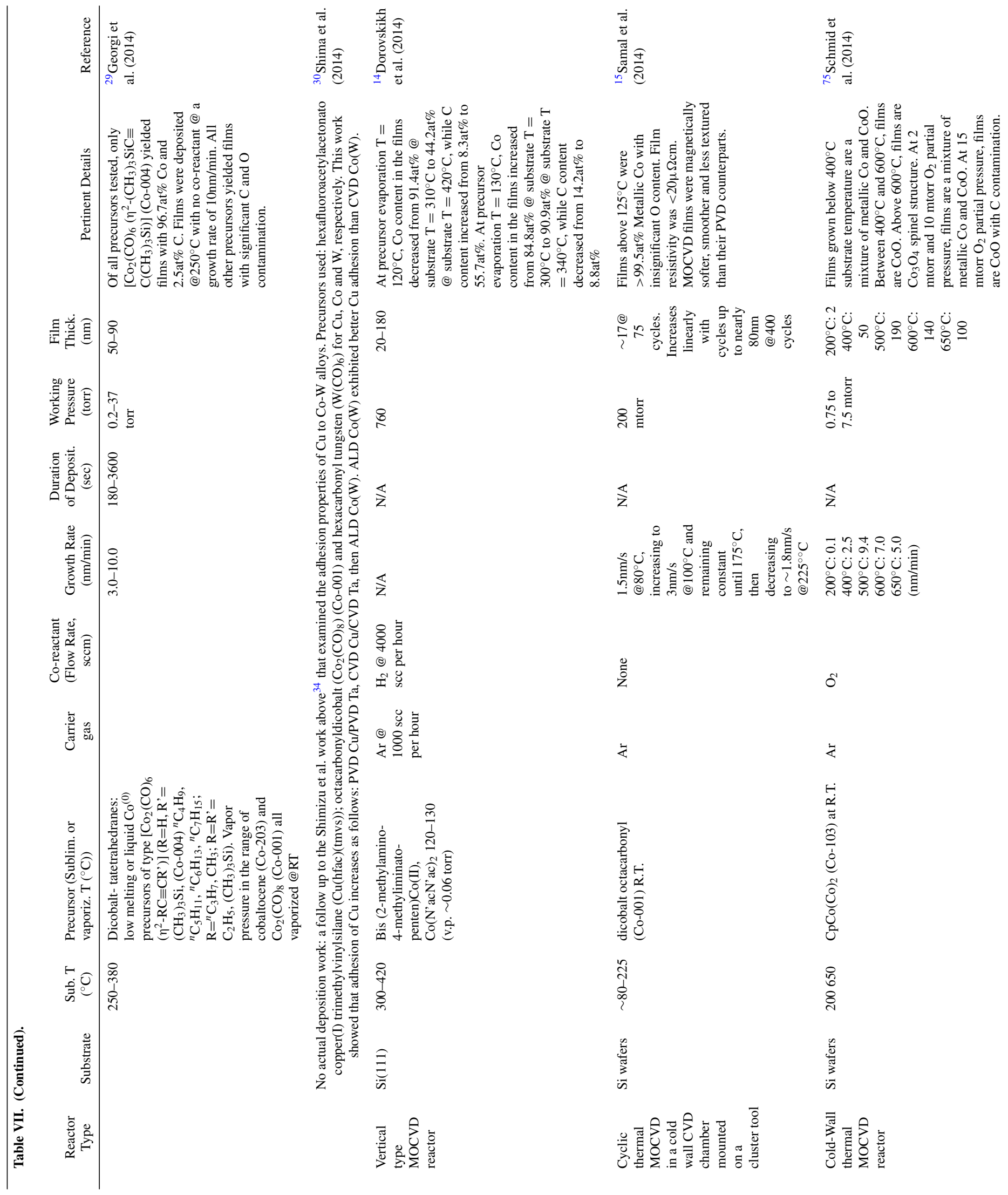




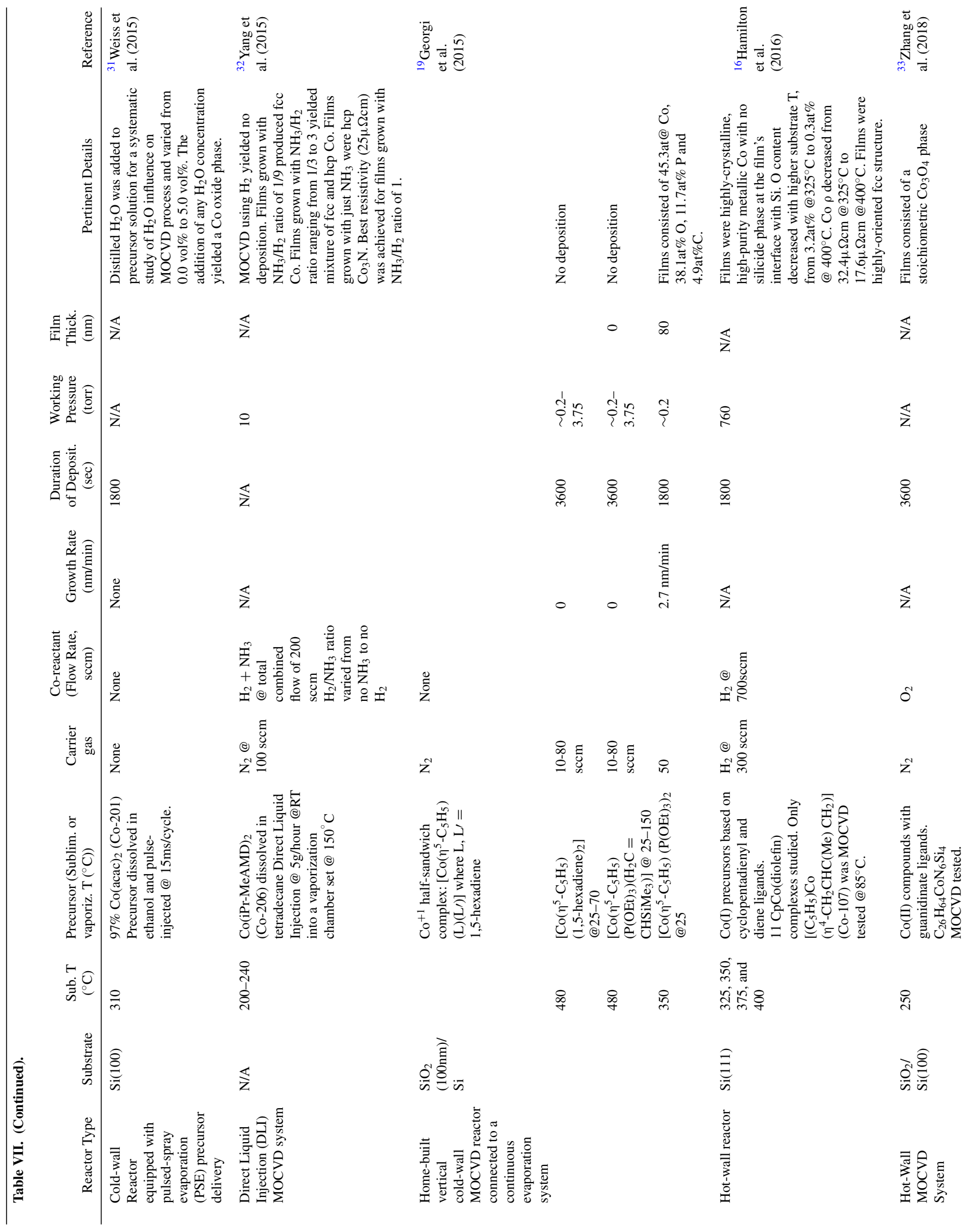




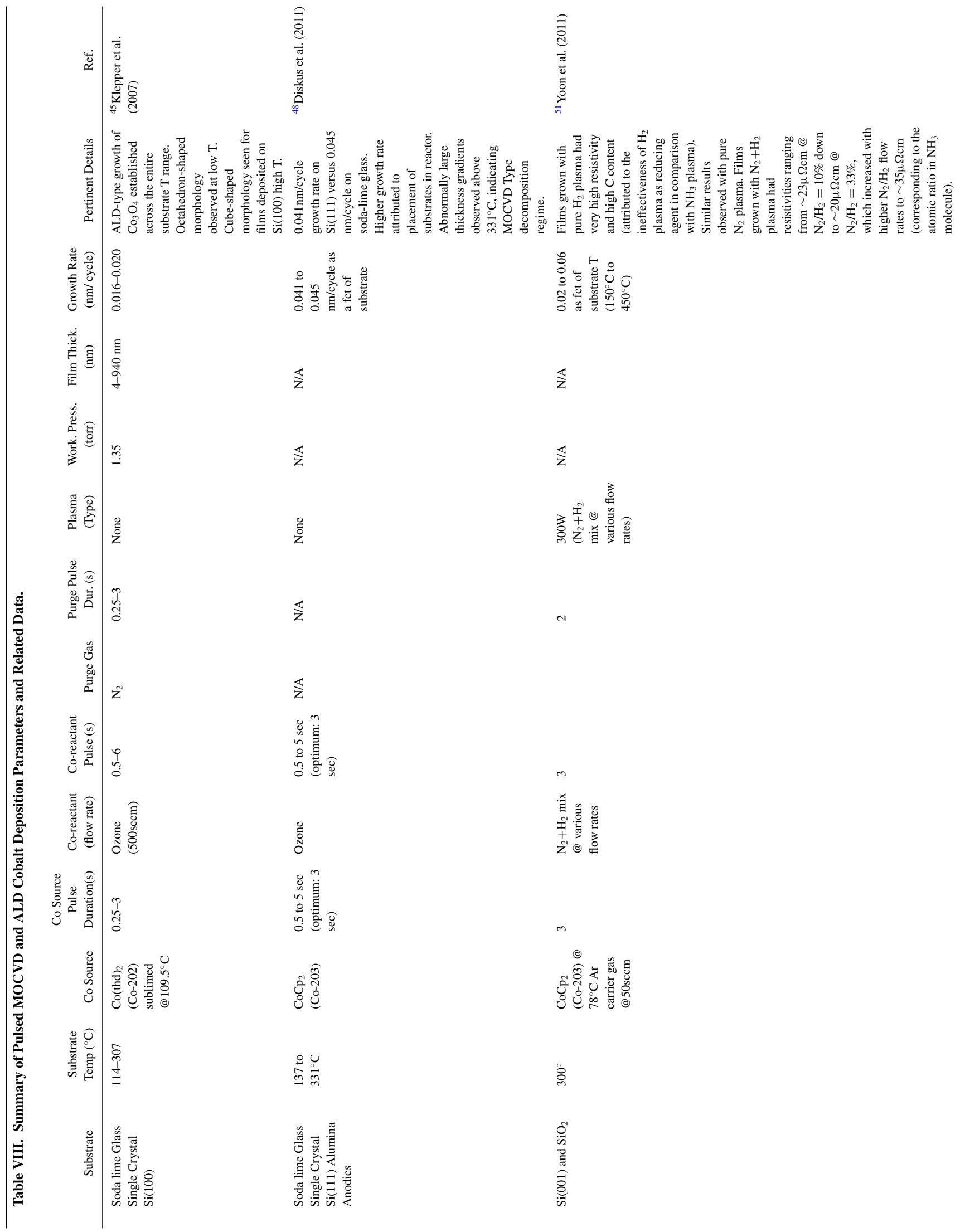


ECS Journal of Solid State Science and Technology, 8 (2) P119-P152 (2019)

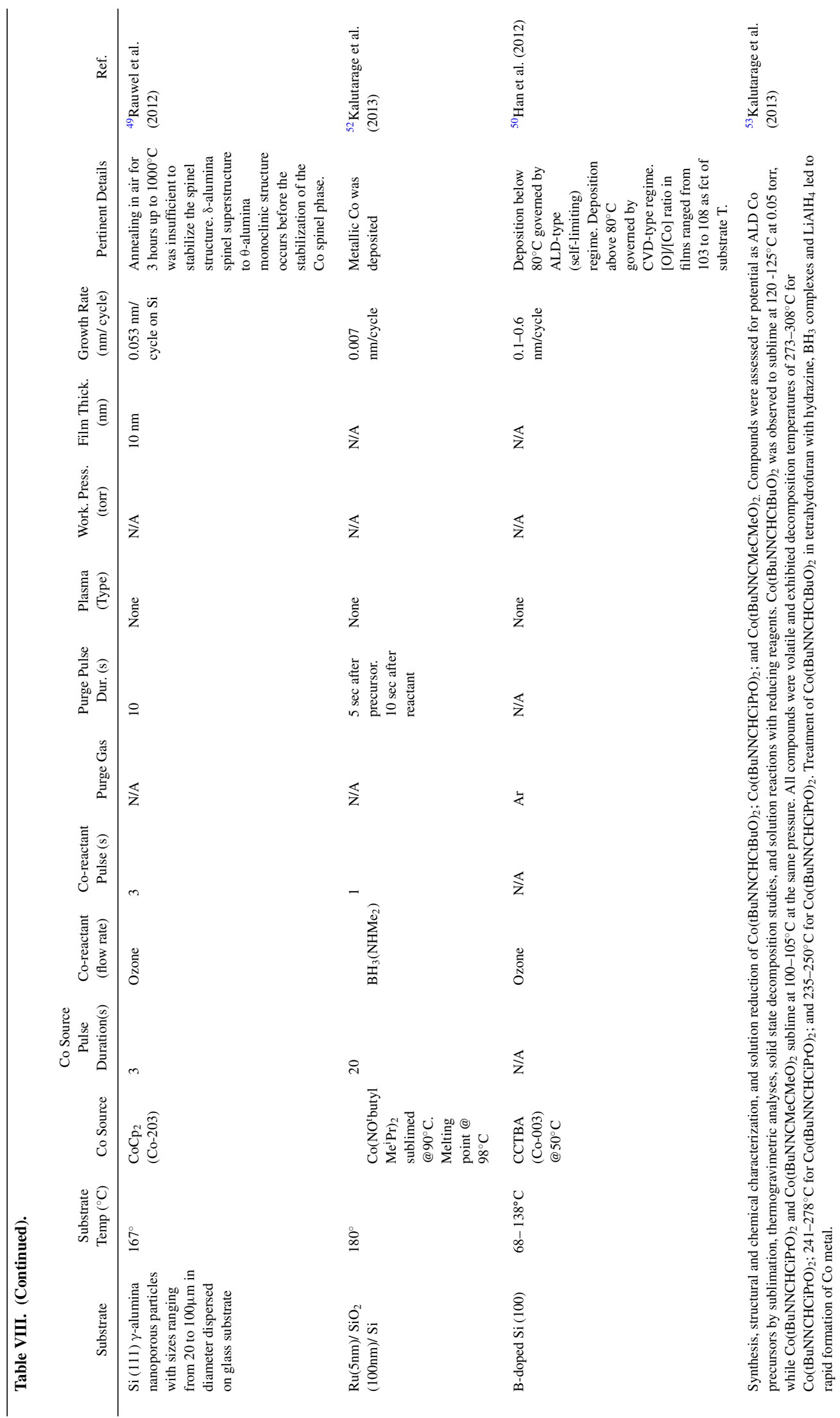




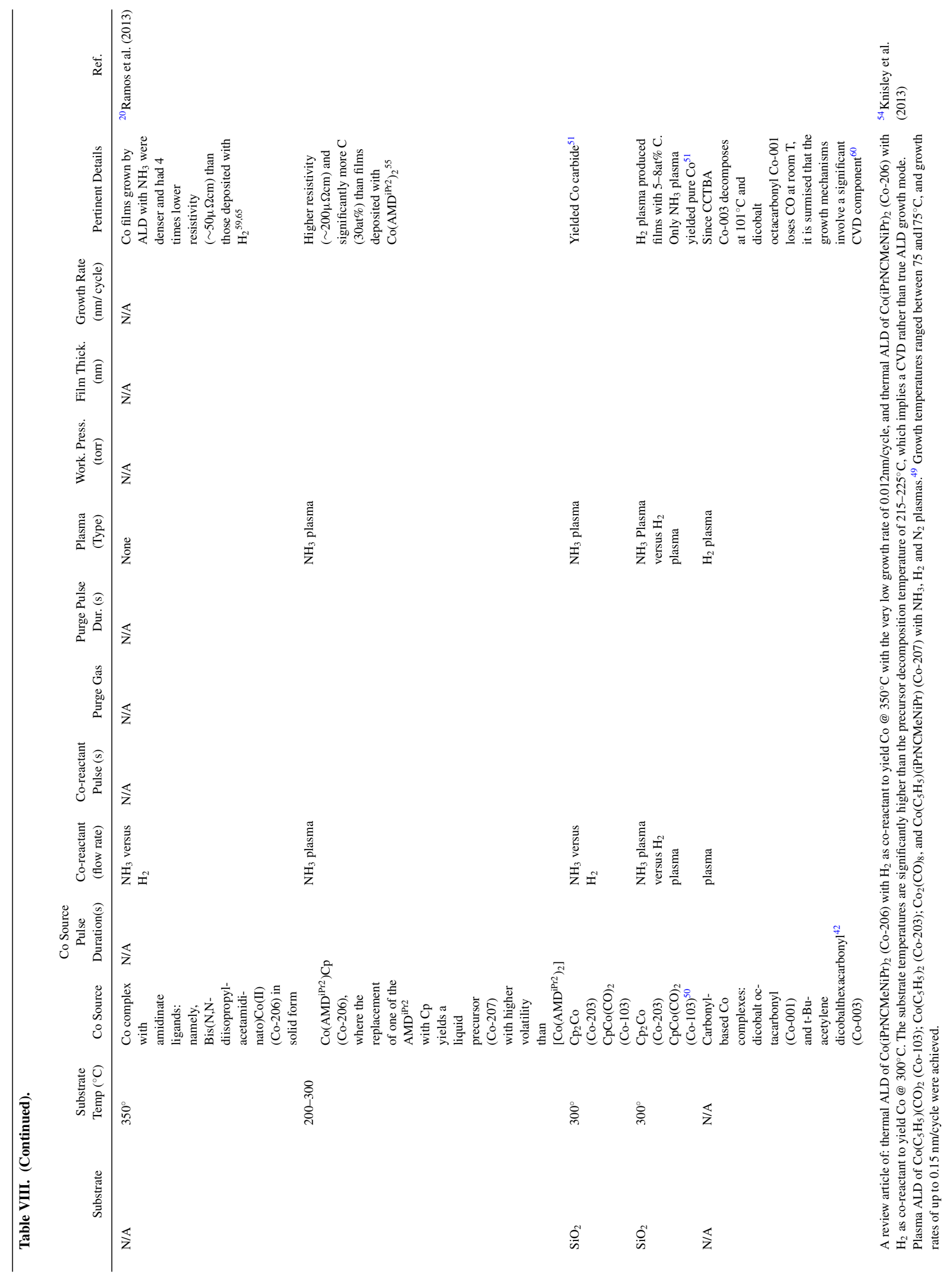




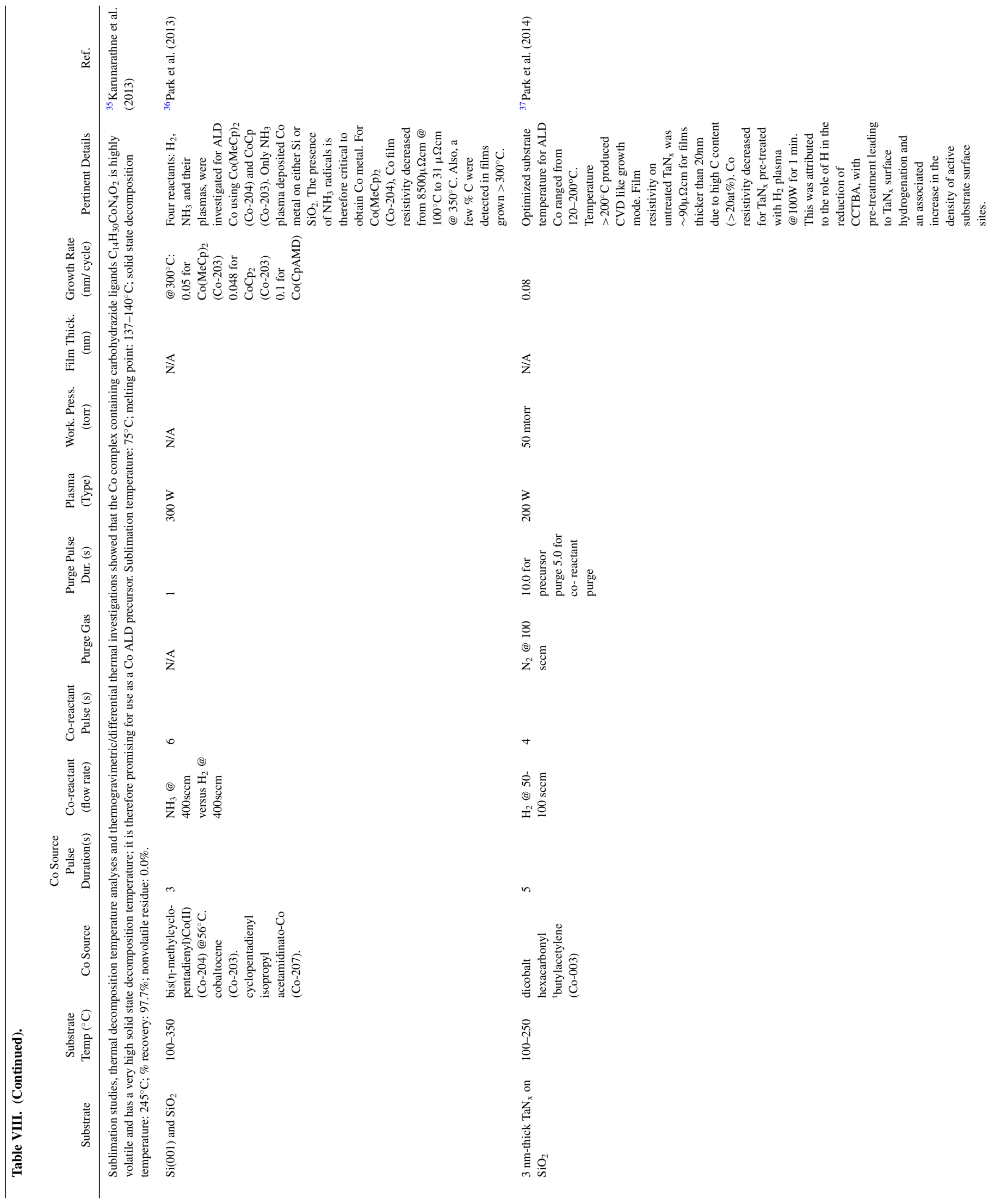




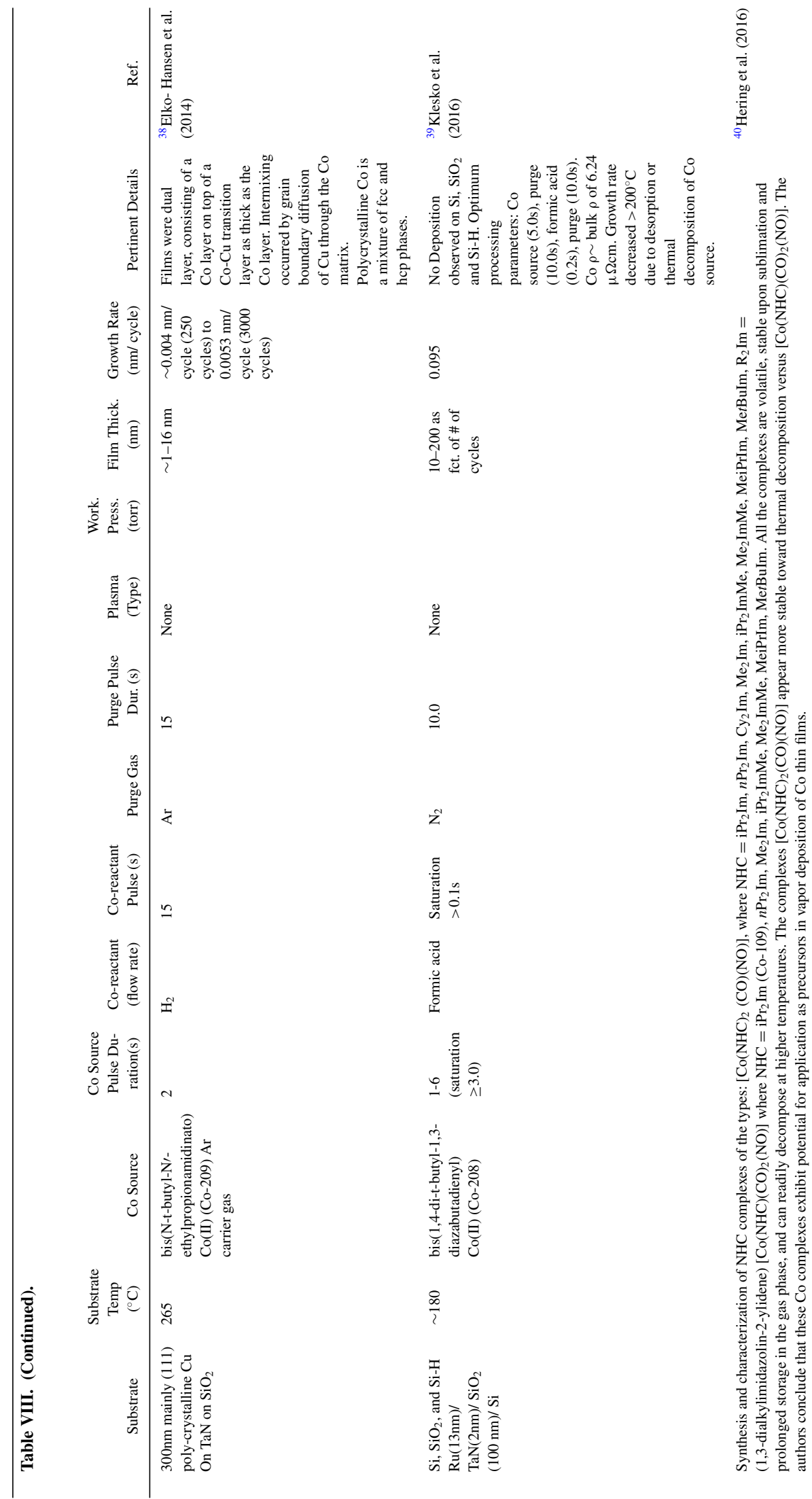




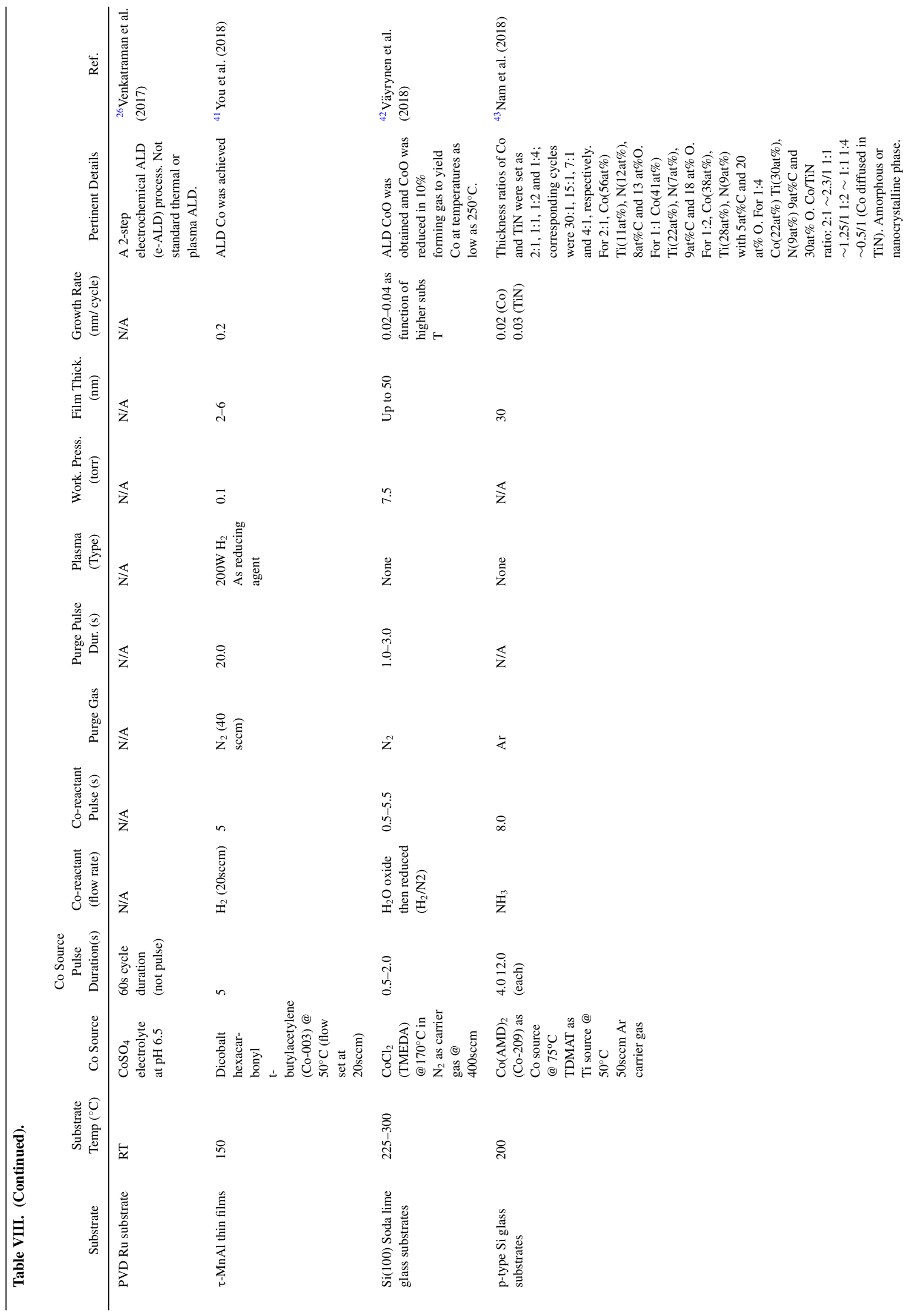




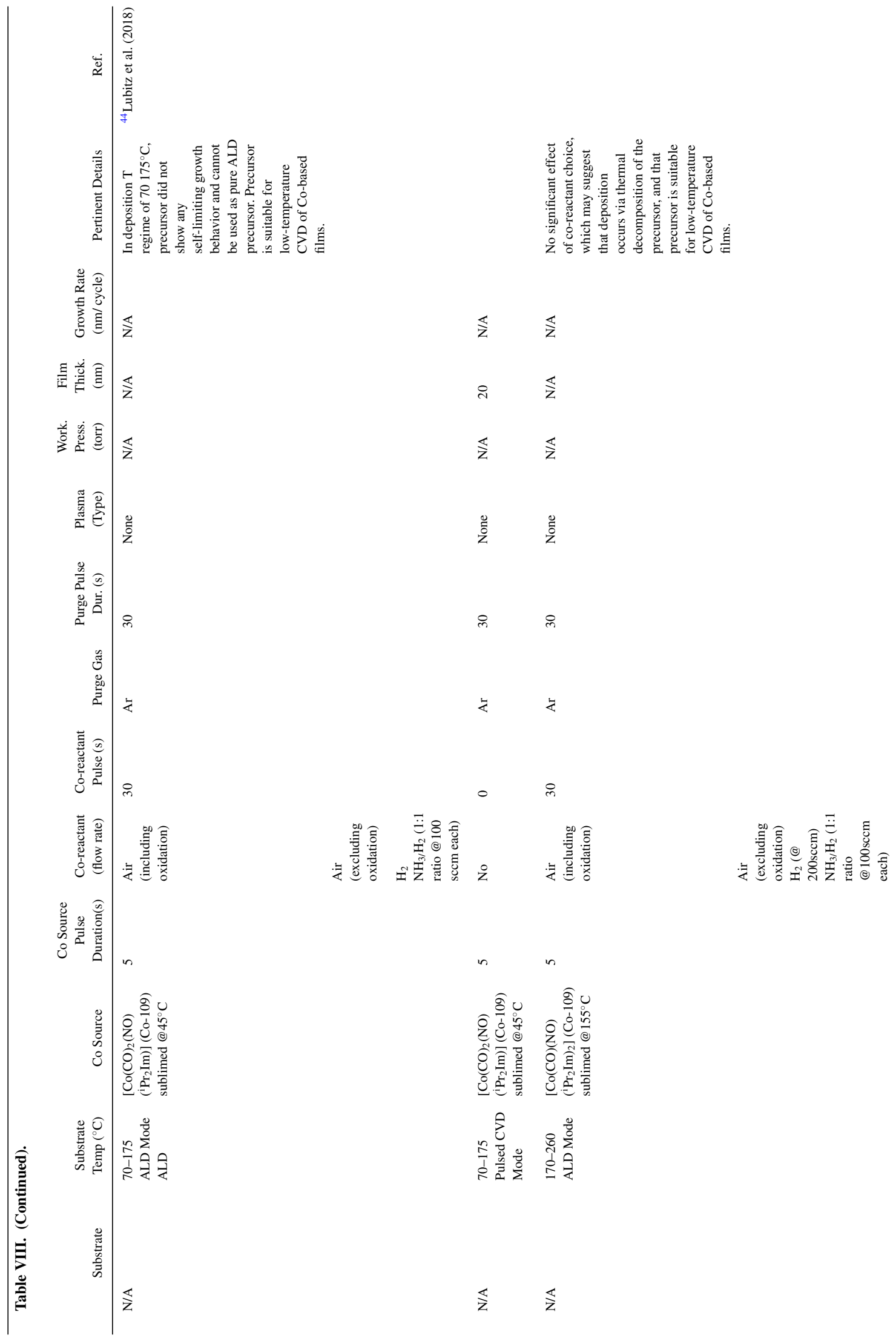




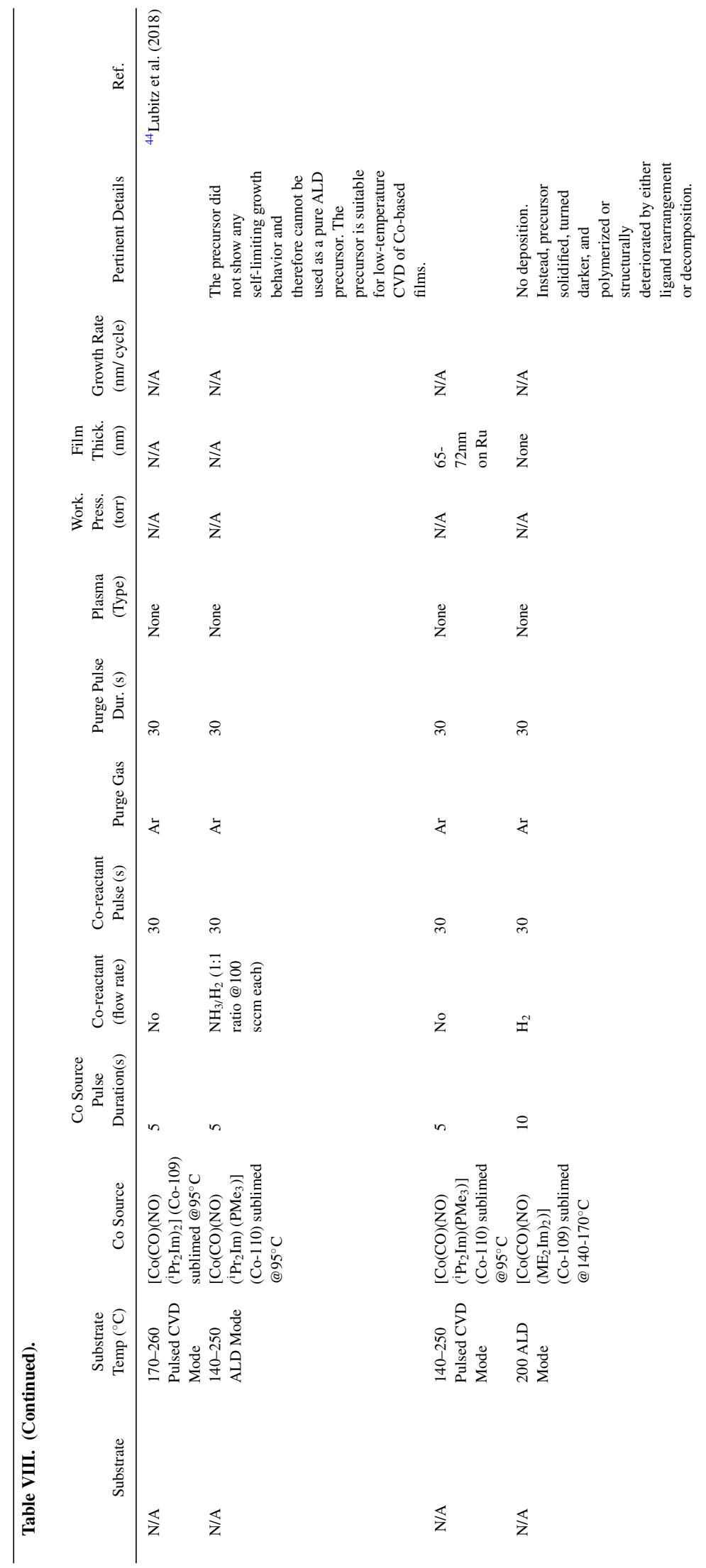




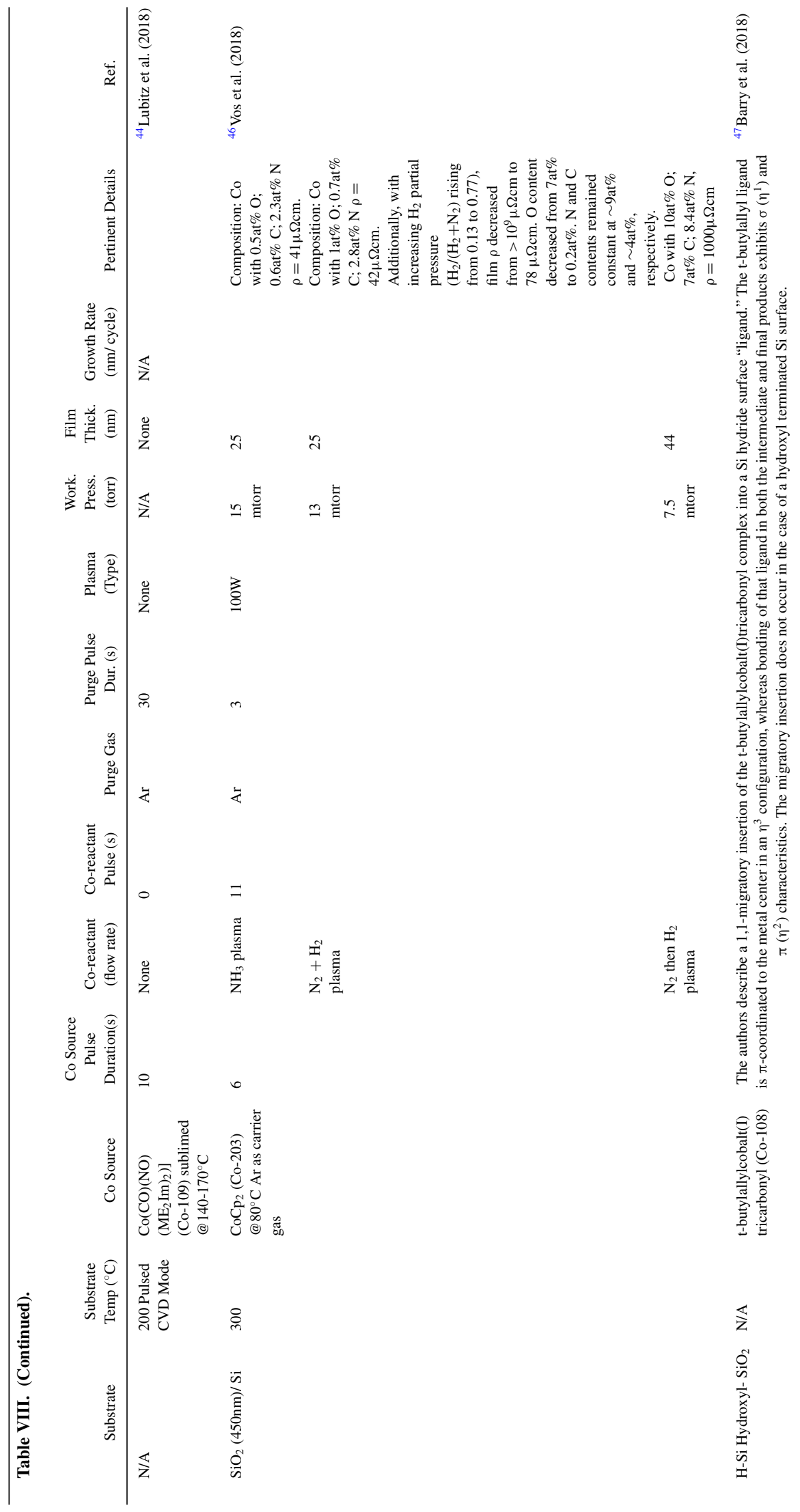




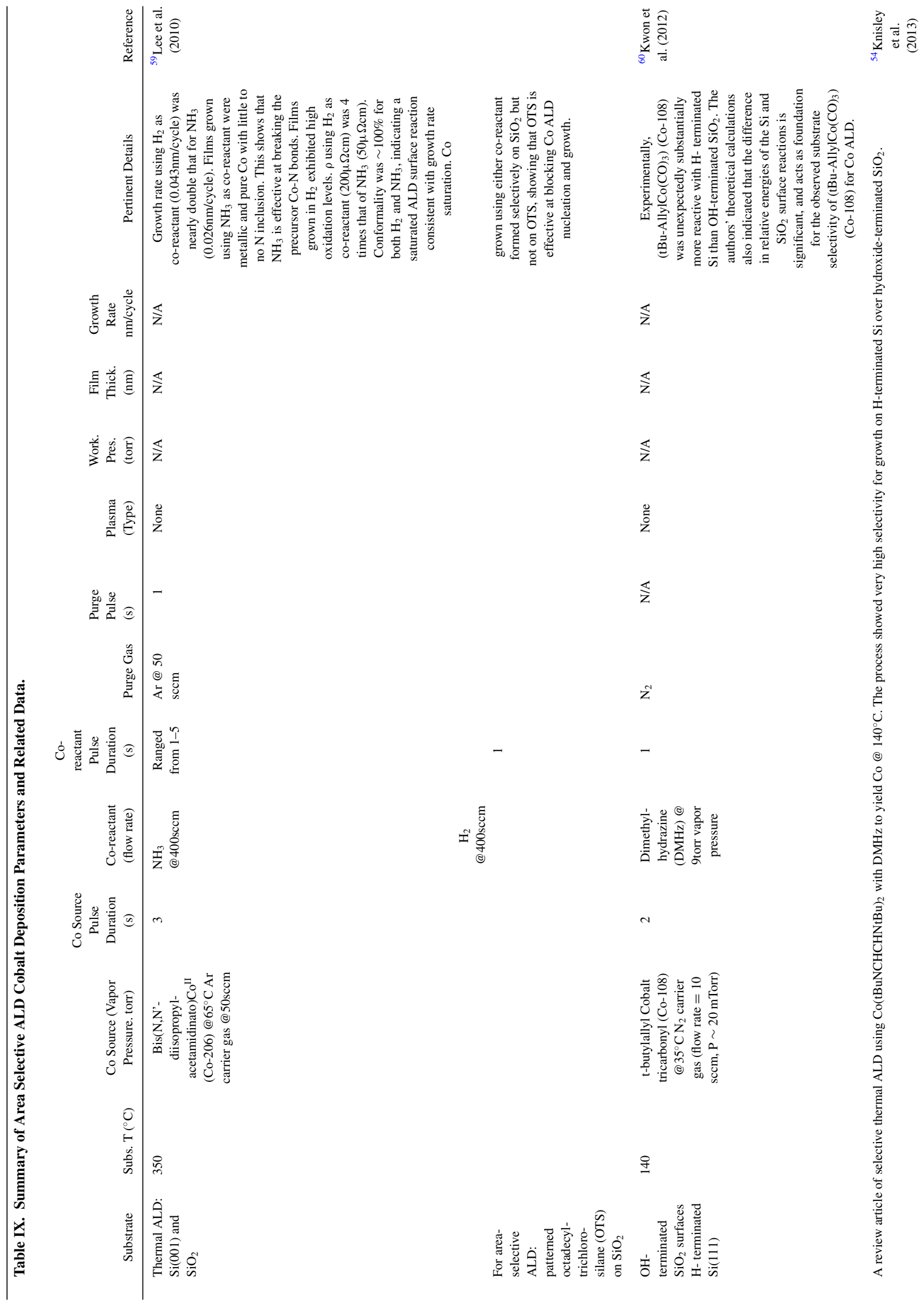




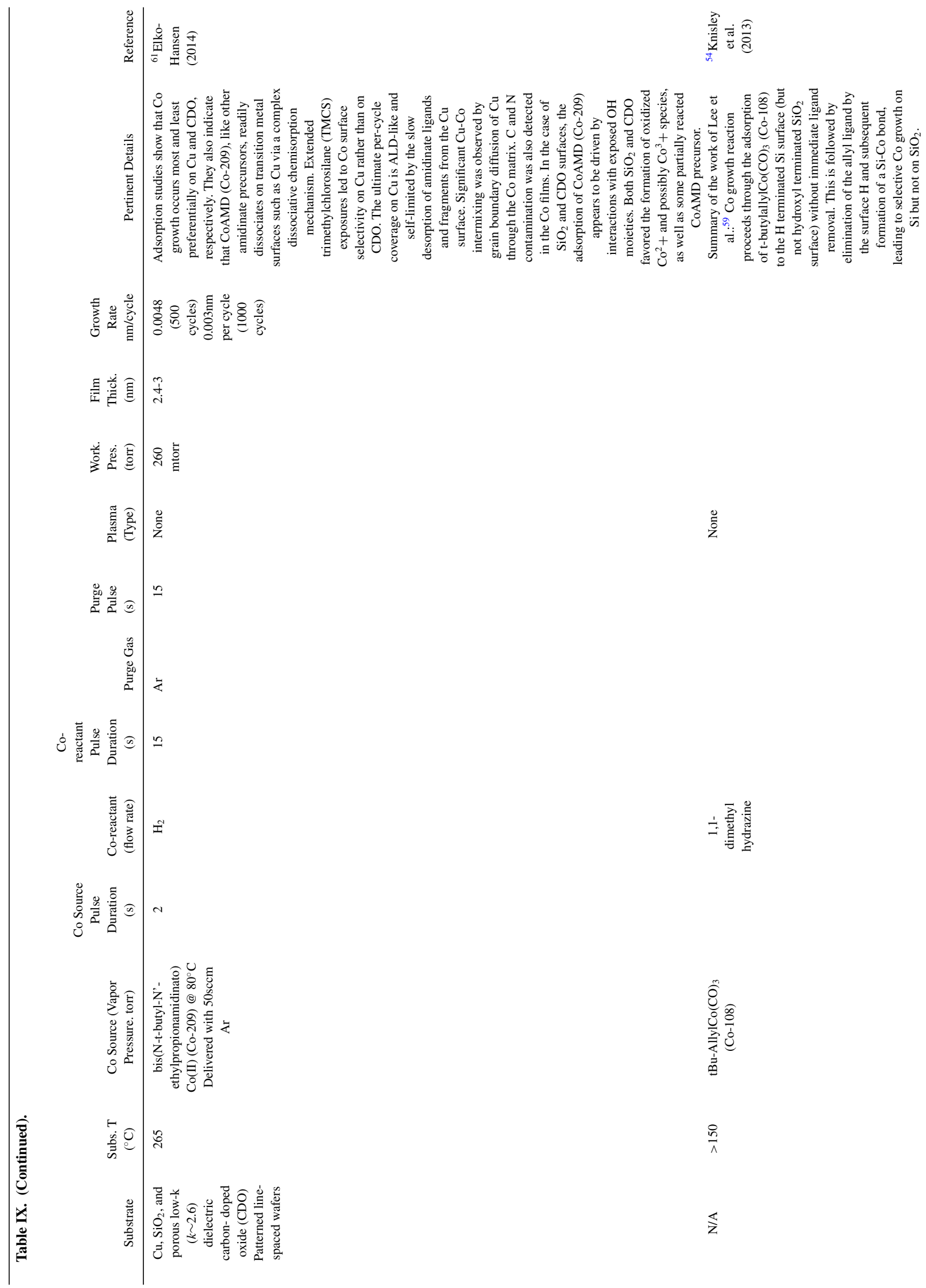




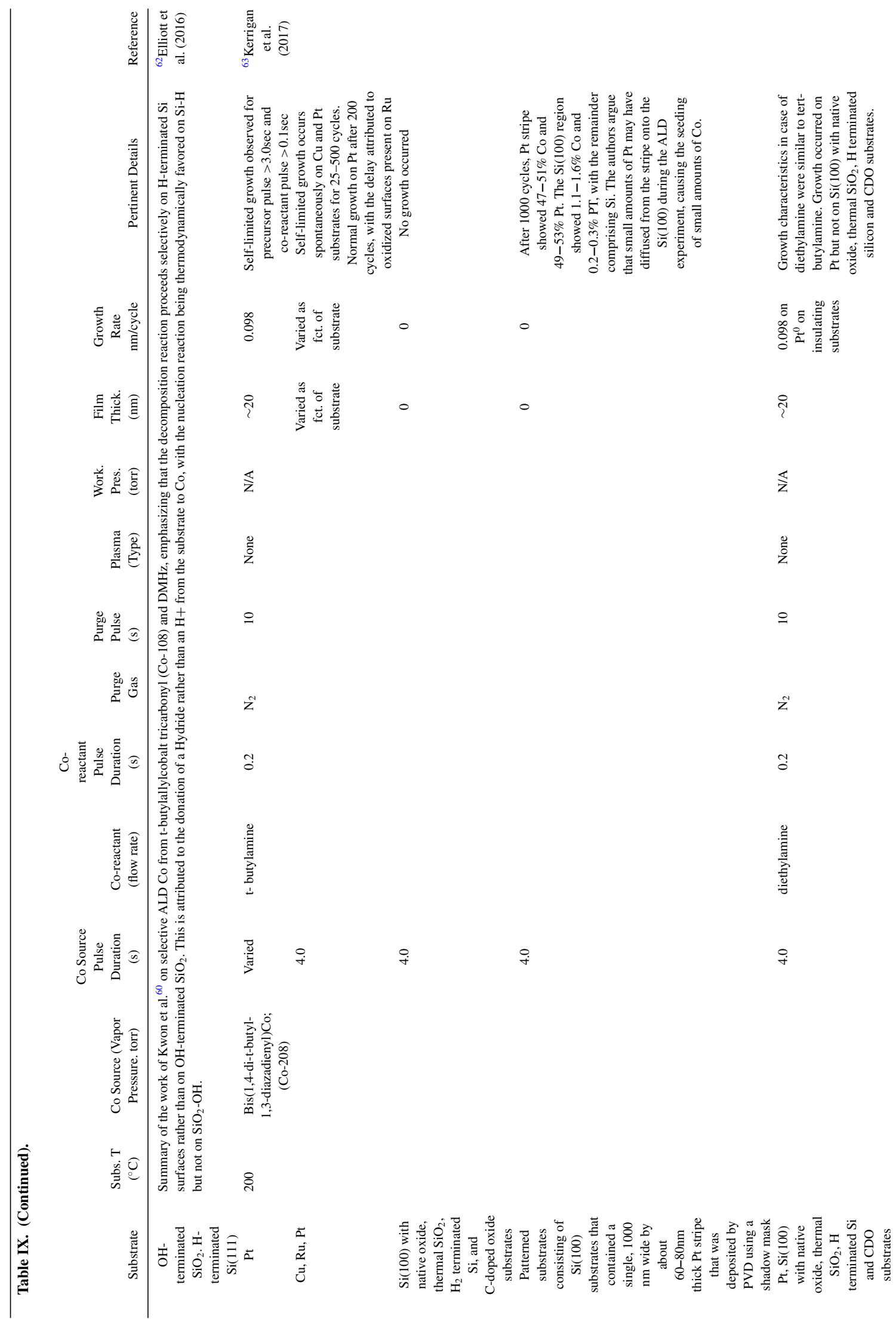




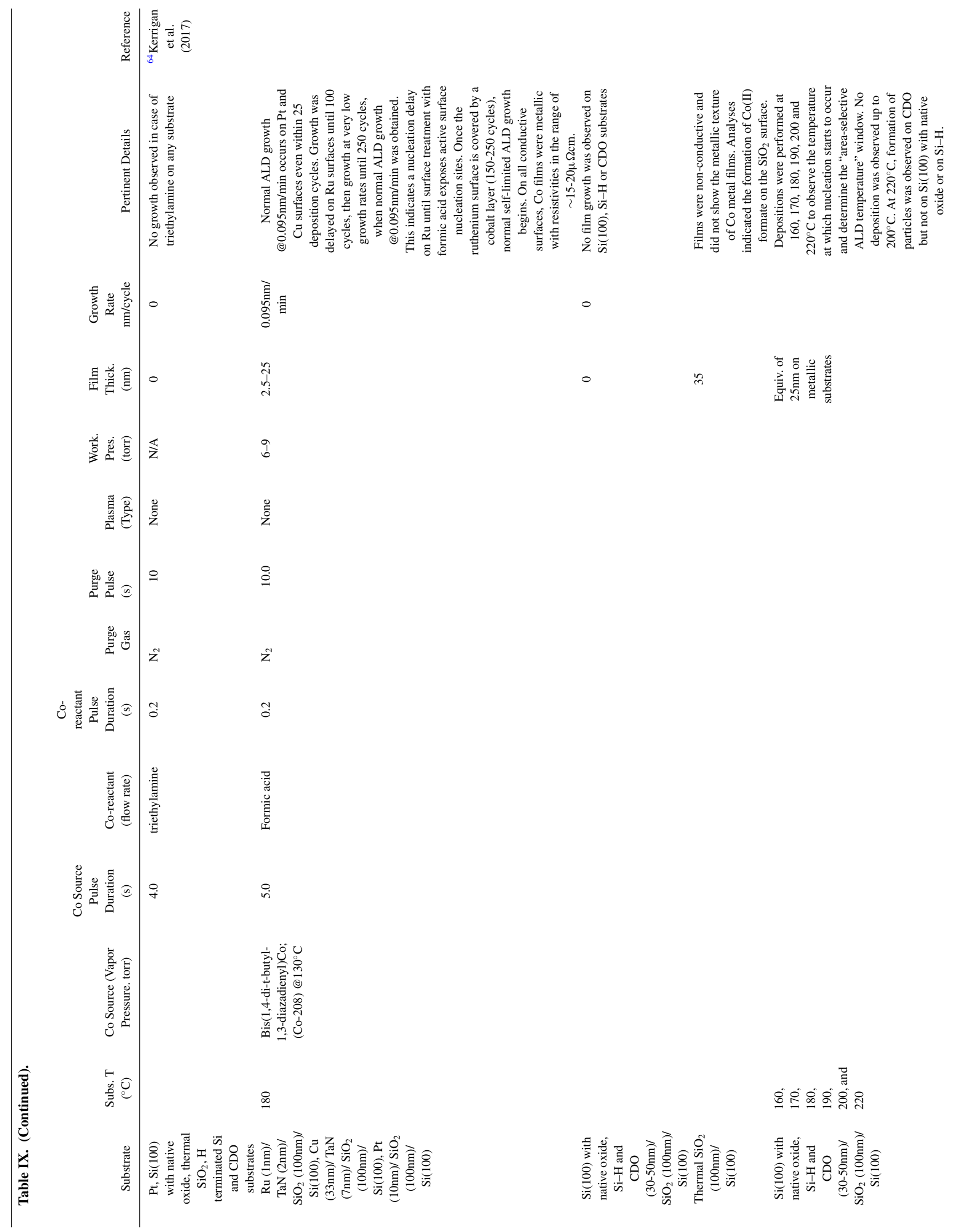




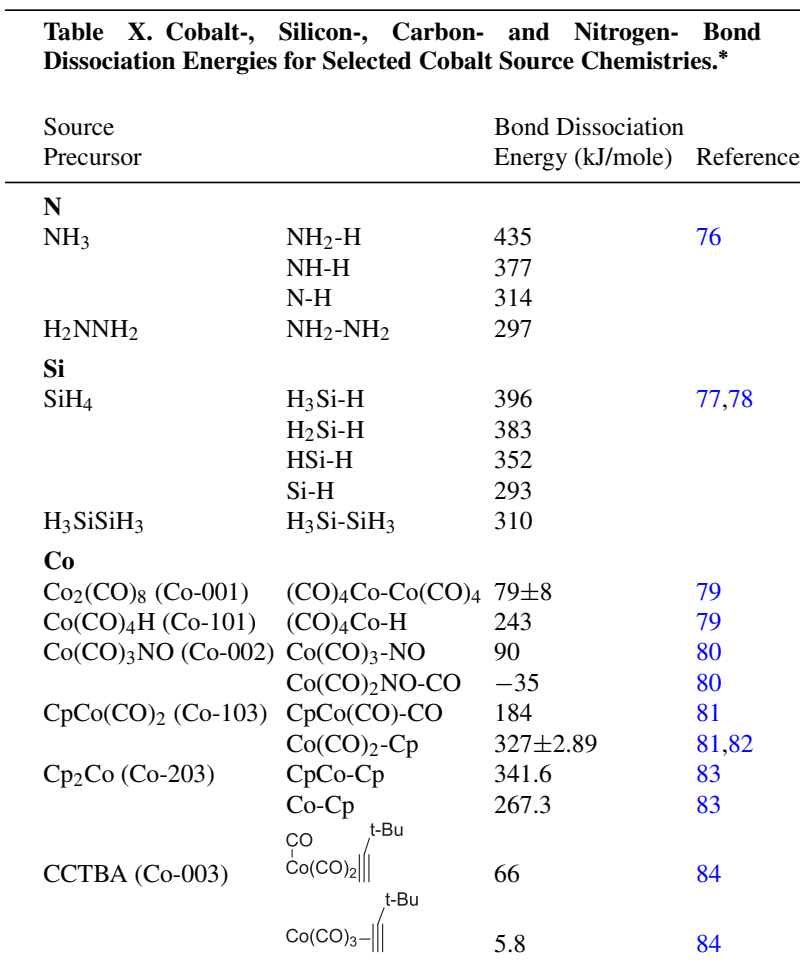

*The table is intended to provide baseline comparisons of bond dissociation energies of selected $\mathrm{Co}, \mathrm{Si}, \mathrm{C}$ and $\mathrm{N}$ chemistries with some common precursors.

terminated $\mathrm{SiO}_{2}$ surfaces, and determined that electron-rich substrate surface sites are needed for precursor adsorption; such sites potentially comprise metals, sub-oxides or reducing agents such as a hydride anion. Substrate surfaces that can act as $\mathrm{H}^{-}$(hydride, not $\mathrm{H}^{+}$) donors to Co to catalyze precursor attachment, decomposition and Co nucleation include $\mathrm{H}-\mathrm{Si}$ but not $\mathrm{OH}-\mathrm{SiO}_{2}$. This explains why the nucleation reaction is thermodynamically favorable on $\mathrm{Si}-\mathrm{H}$ but not on $\mathrm{SiO}_{2}-\mathrm{OH}$ surfaces - a phenomenon attributed to the distinct $\mathrm{H}$ donor abilities of the former-as well as the resulting area-selective deposition observed on $\mathrm{Si}$ but not on $\mathrm{SiO}_{2}$.

Phase II introduced $\mathrm{H}_{2}$ as a co-reactant and examined its effects as a reducing agent. Since $\mathrm{H}_{2}$ can act as both a proton and hydride donor, it could be applied simultaneously to both remove precursor ligands from the substrate surface and act as a reducing agent for the Co metal center. The authors refer to this as reductive elimination of ligands by hydrogenation. ${ }^{8}$ However, $\mathrm{H}_{2}$ dissociation to yield either atomic radicals or the hydride anion is energetically favorable both at high temperatures, through the application of a plasma, and/or on substrate surfaces that enable such dissociative reaction. In any case, molecular $\mathrm{H}_{2}$ can act effectively to reduce oxide-covered surfaces. In the case of ALD cobalt, since cobalt hydride is unstable, the role of hydrogen is limited to the first precursor exposure step and ends when precursor ligands are removed and the substrate surface is covered with cobalt in what Elliott et al. refer to as an "abbreviated cycle." At the next exposure step, the precursor undergoes molecular or dissociative adsorption onto the bare cobalt surface, leaving the latter quite vulnerable to the incorporation of gas phase or precursor ligand contaminants such as $\mathrm{O}$. Growth rates are also appreciably limited in this case.

Phase III analyzed co-reactants, one of which came from a family of reducing co-reactants where the hydride is bound to a metal or semimetal center, such as hydrosilanes, hydroboranes, and hydroalanes. Unlike $\mathrm{H}_{2}$, the benefit of these reagents is their ability to continue to adsorb and yield a hydride-covered cobalt surface even after the first cycle of ligand removal and cobalt deposition. The resulting precursor reduction process with every exposure cycle should, in principle, lead to the deposition of pure cobalt void of impurities. These hydrides also have the advantage of promoting a significantly higher growth rate than that achieved in the case of the abbreviated cycle discussed above, in which the growth rate is limited by the instability of cobalt hydride.

Elliott et al. also discuss the potential of zero-valent cobalt precursors as attractive sources for Co CVD, arguing that, since the Co source precursor would not necessitate reduction, the role of the co-reactants would simply be to eliminate ligands via an oxidation process - similarly to ALD using an $\mathrm{O}_{2}$-plasma to grow oxides. They further hypothesize that ligand oxidation would not produce transient $\mathrm{OH}$ species on the substrate surface, and conclude that Brønsted acidic amines may be viable co-reactants for zero-valent cobalt precursors.

\section{Metal-Organic Chemical Vapor Deposition (MOCVD)}

Tables IV and VII present a synopsis of thermal MOCVD Co applications, processing parameters, post-processing treatments (where applicable) and pertinent findings. A review of Tables IV and VII shows the following common trends in recent MOCVD work:

MOCVD Co films are employed as contact material in MOS field effect transistors (MOSFET) in conventional IC applications such as $\mathrm{CoSi}_{2}$, as a diffusion barrier for $\mathrm{Cu}$ in multilevel metallization schemes, as effective adhesion layers (Co or Co-based alloys) in $\mathrm{Cu}$ interconnects, and as a wetting layer to induce void-free filling of narrow copper lines by reflow of nonconformal $\mathrm{Cu}$. There are also several emerging uses for MOCVD Co films related to the Co magnetic dipole moment, such as spintronic and GMR devices and spin valves. MOCVD Co nanostructures are also applied as active materials in sensors, reflective and refractive coatings for optical devices, seed material for the growth of carbon nanotubes, as catalysts for self-aligned nanowires and in the Fischer-Tropsch (FT) process. Finally, MOCVD Co continues to be incorporated more widely as antibacterial, decorative, protective and wear-resistant coating.

Cold-wall and hot-wall thermal MOCVD processes appear to be the exclusive methods for cobalt deposition. No plasma activation or enhancement of any kind was used, perhaps due to concerns over the incorporation of contaminants into the resulting Co films. Various cobalt precursors with oxidation states ranging from 0 to 2 were utilized with a substrate temperature in the range of 80 $480^{\circ} \mathrm{C}$, with most processes reportedly occurring between $225^{\circ} \mathrm{C}$ and $350^{\circ} \mathrm{C}$. Co-reactants included $\mathrm{H}_{2}, \mathrm{NH}_{3},\left(\mathrm{H}_{2}+\mathrm{NH}_{3}\right)$ mixture and oxygen $\left(\mathrm{O}_{2}\right)$, while carrier gases were primarily inert-namely argon (Ar) or nitrogen $\left(\mathrm{N}_{2}\right)$ - though a limited number of reports employed $\mathrm{H}_{2}$. Noteworthy investigations and associated findings are discussed below.

Significant research activities have explored the development of new MOCVD precursor transport and supply methods to the reaction zone. Innovative precursor delivery techniques include: (i) pulsed liquid injection (PLI) ${ }^{67}$ or pulsed-spray evaporation (PSE); $; 81$ (ii) continuous evaporation; ${ }^{18,19}$ (iii) direct liquid evaporation (DLE). ${ }^{32}$

- In the PSE approach, the precursor, which is typically in solid form, is dissolved in a solvent and pulse-injected into the reactor at a predetermined frequency. Examples include a mixture of $(0.05 \mathrm{M})$ $\mathrm{Co}$ (thd) $)_{2}$ and 1,2-dimethoxyethane (monoglyme) which was pulseinjected at a frequency of $2 \mathrm{~Hz} ; \mathrm{Co}(\mathrm{acac})_{2}(\mathrm{Co}-201)$ which was dissolved in ethanol and pulsed-injected at frequencies ranging from $15 \mathrm{~ms} /$ cycle $^{31}$ to $40 \mathrm{~ms} /$ cycle. $^{8}$

- Continuous evaporation is a method based on the incorporation of a vaporizer unit that supplies a constant and controlled flow of a $\mathrm{Co}^{(0)}$ precursor / carrier gas mixture into the MOCVD reactor. ${ }^{18}$ The selection of low melting temperature or liquid $\mathrm{Co}^{\left({ }^{\circ}\right)}$ 
precursors of the type $\left[\mathrm{Co}_{2}(\mathrm{CO})_{6}\left(\eta^{2}-\mathrm{RC} \equiv \mathrm{CR}^{\prime}\right)\right]\left(\mathrm{R}=\mathrm{H}, \mathrm{R}^{\prime}=\left(\mathrm{CH}_{3}\right)_{3} \mathrm{Si}\right.$ (Co-004), ${ }^{n} \mathrm{C}_{4} \mathrm{H}_{9},{ }^{n} \mathrm{C}_{5} \mathrm{H}_{11},{ }^{n} \mathrm{C}_{6} \mathrm{H}_{13},{ }^{n} \mathrm{C}_{7} \mathrm{H}_{15} ; \mathrm{R}={ }^{n} \mathrm{C}_{3} \mathrm{H}_{7}, \mathrm{R}=\left(\mathrm{CH}_{3}\right)_{3} \mathrm{Si}$, $\left.\mathrm{CH}_{3} ; \mathrm{R}=\mathrm{R}^{\prime}=\mathrm{C}_{2} \mathrm{H}_{5},\left(\mathrm{CH}_{3}\right)_{3} \mathrm{Si}\right)$; and $\mathrm{R}={ }^{n} \mathrm{C}_{3} \mathrm{H}_{7}, \mathrm{R}^{\prime}=\left(\mathrm{CH}_{3}\right)_{3} \mathrm{Si}, \mathrm{CH}_{3}$; $\left.\mathrm{R}=\mathrm{R}^{\prime}=\mathrm{C}_{2} \mathrm{H}_{5},\left(\mathrm{CH}_{3}\right)_{3} \mathrm{Si}\right)$ allows the vaporizer to be maintained at room temperature. ${ }^{19}$

- In direct liquid evaporation, a precursor solution is vaporized by flowing it through a hot coil placed inside an oven, exploiting the almost instantaneous heat exchange between the heated solid loop and the liquid mixture to evaporate and deliver both the precursor and carrier gas efficiently and controllably to the reaction zone. The design and size of the tube force any non-volatile byproducts of the vaporization process to adhere to the bottom of the tube instead of contaminating the reactor, while the diameter of the tube orifice into the reactor prevents any clogging or blockage. In one embodiment, bis(N,N'-diisopropylacetamidinato) $\mathrm{Co}^{\text {(II) }}(\mathrm{Co}-206)$ was dissolved in tetradecane and injected through a vaporization chamber set at $150^{\circ} \mathrm{C}$.

All these delivery techniques share common advantages that include precursor storage at room temperature, which minimizes any thermally-induced decomposition effects resulting from long-term storage in a heated traditional bubbler as well as the ability to accurately and effectively control precursor flow rate into the MOCVD reactor.

A number of studies have also examined the role of additives in precursor decomposition mechanisms and the resulting Co film morphology and properties. For instance, Premkumar et al. ${ }^{8}$ compared the effects of isopropanol and n-propanol in MOCVD Co from $\mathrm{Co}(\mathrm{acac})_{2}$ (Co-201), determining that the former yielded $\mathrm{Co}_{2} \mathrm{C}$ at substrate temperatures in the range of $205-230^{\circ} \mathrm{C}$, while the latter produced metallic $\mathrm{Co}$ at temperatures above $250^{\circ} \mathrm{C}$. Weiss et al. ${ }^{31}$ examined the addition of water to a solution of $\mathrm{Co}(\mathrm{acac})_{2}$ (Co-201) in ethanol to investigate the effects of humidity on precursor stability and MOCVD performance, concluding that water inclusion at any concentration led to the growth of a Co oxide phase.

Similar to the early MOCVD work by Ivanova et al. ${ }^{3}$ that yielded pure metallic Co from the source precursor cobalt tricarbonyl nitrosyl (Co-002), investigators have reported the growth of pure metallic cobalt from a number of cobalt sources, including:

- Dicobalt hexacarbonyl t-butylacetylene (Co-003) with $\mathrm{H}_{2}$ as coreactant at a substrate temperature of $150^{\circ} \mathrm{C}$ (Co oxidation state: 0 ; key parameter: high $\mathrm{H}_{2}$ partial pressure in the reaction zone). ${ }^{10}$

- Isopropyl derivative $\mathrm{CpCo}\left({ }^{\mathrm{i}} \mathrm{Pr}_{2}\right.$-dab) $(\mathrm{Co}-302)$ with $\mathrm{H}_{2}$ as coreactant at a substrate temperature above $325^{\circ} \mathrm{C}$ (Co oxidation state: 3; key parameter: substrate temperature). ${ }^{17}$

- Dicobalt hexacarbonyl bis(trimethylsilyl)acetylene (Co-005) with no co-reactant at a substrate temperature above $250^{\circ} \mathrm{C}$ (Co oxidation state: 0 ; key parameters: type of precursor and substrate temperature). ${ }^{29}$

- Dicobalt octacarbonyl $\left[\mathrm{Co}_{2}(\mathrm{CO})_{8}\right](\mathrm{Co}-001)$ with no co-reactant at a substrate temperature above $125^{\circ} \mathrm{C}$ (Co oxidation state: 0 ; key parameter: substrate temperature). ${ }^{15}$

- $\mathrm{Bis}\left(\mathrm{N}, \mathrm{N}^{\prime}\right.$-diisopropylacetamidinato)cobalt(II)) (Co-206) dissolved in tetradecane with $\left(\mathrm{NH}_{3}+\mathrm{H}_{2}\right)$ mixture at a ratio of 1:1 and a substrate temperature in the range $200-240^{\circ} \mathrm{C}$ (Co oxidation state: 2; key parameter: $\mathrm{NH}_{3} / \mathrm{H}_{2}$ ratio). ${ }^{32}$

- Co precursor based on cyclopentadienyl and diene ligands $\left[\left(\mathrm{C}_{5} \mathrm{H}_{5}\right) \mathrm{Co}\left(\eta^{4}-\mathrm{CH}_{2} \mathrm{CHC}(\mathrm{Me}) \mathrm{CH}_{2}\right)\right]$ with $\mathrm{H}_{2}$ as co-reactant at a substrate temperature of $400^{\circ} \mathrm{C}$ (Co oxidation state: 1; key parameter: substrate temperature). ${ }^{16}$

Co-W alloy thin films were also deposited by MOCVD from the coreaction of dicobalt octacarbonyl (Co-001) and tungsten hexacarbonyl $\left[\mathrm{W}(\mathrm{CO})_{6}\right]$ as Co and $\mathrm{W}$ sources, respectively. The resulting alloys were then tested as a diffusion barrier in IC Cu metallization, ${ }^{34}$ and the addition of $\mathrm{W}$ was shown to improve the barrier properties of the resulting CoW films against $\mathrm{Cu}$ diffusion. In particular, the addition of $20 \mathrm{at} \% \mathrm{~W}$ to the Co matrix produced diffusion resistance behavior equivalent to physical vapor deposition (PVD) Ta. However, film resistivity was significantly higher than metallic Co.

\section{Atomic Layer Deposition (ALD) and Pulsed MOCVD}

Tables V and VIII present a synopsis of pulsed MOCVD and ALD Co applications, processing parameters, post-processing treatments (where applicable) and pertinent findings. A review of Tables $\mathrm{V}$ and VIII shows the following common trends in recent pulsed MOCVD and ALD work:

Pulsed MOCVD and ALD Co films are also proposed for applications in traditional IC products, including as capping, adhesion and diffusion barrier layers in $\mathrm{Cu}$ interconnect structures, and as seed layers to catalyze $\mathrm{Cu}$ electroplating; $\mathrm{CoSi}_{2}$ as contact material in $\mathrm{Si}$ transistors, and as a replacement for $\mathrm{Cu}$ interconnects in emerging nanoscale IC devices. New usages are also being explored that exploit cobalt's magnetic dipole moment, such as the soft magnet phase of magnetically exchanged coupled magnets consisting of hard and soft magnetic phases, non-volatile magneto-resistive random access memories (MRAMs), GMR devices and spin valves, and magnetic alloys. Additional applications encompass cutting-wear resistant alloys and super alloys, as well as amorphous metal alloys, also referred to as metallic glasses due to their special features such as high hardness and unique electrical properties.

Cold-wall and hot-wall thermal and plasma-enhanced ALD and pulsed MOCVD processes were all investigated for cobalt deposition. Various cobalt precursors with oxidation states ranging from 0 to 3 were utilized with substrate temperatures in the range of $70-350^{\circ} \mathrm{C}$, with most processes reported occurring between $150^{\circ} \mathrm{C}$ and $350^{\circ} \mathrm{C}$. Co-reactants included $\mathrm{H}_{2}, \mathrm{NH}_{3},\left(\mathrm{H}_{2}+\mathrm{NH}_{3}\right)$ mixture and forming gas $\left(\mathrm{H}_{2} / \mathrm{N}_{2}\right)$, while carrier gases consisted primarily of inert gases, namely argon (Ar) or nitrogen $\left(\mathrm{N}_{2}\right)$, with a limited number of reports employing $\mathrm{H}_{2}$. Exotic ALD methods to Co deposition included liquid phase (electroplating) in what the authors referred to as electroplating ALD (e-ALD), and two-step ALD involving the growth of $\mathrm{CoO}$ which was then reduced in forming gas to Co metal. Noteworthy investigations and associated findings are discussed below.

Significant plasma-enhanced (PE-ALD) research activities examined the role of plasma-activated co-reactants in the adsorption, reaction and decomposition of Co source precursors to yield metallic Co. Metallic Co was reported by a number of investigators from various Co sources, including:

- $\mathrm{CoCp}_{2}(\mathrm{Co}-203)$ with a $\left(\mathrm{N}_{2}+\mathrm{H}_{2}\right)$ plasma at $300^{\circ} \mathrm{C} ; \mathrm{a} \mathrm{N}_{2} / \mathrm{H}_{2}$ flow ratio of $33 \%$ produced metallic Co with the lowest resistivity $(20 \mu \Omega \mathrm{cm})$. The authors point out that this percentage corresponds to the atomic ratio in $\mathrm{NH}_{3}$ molecule and argue for the importance of $\mathrm{NH}_{3}$ radicals in the clean cleavage of $\mathrm{CoCp}_{2}(\mathrm{Co}-203)$ to yield Co. ${ }^{51}$ The same finding was reported with $\mathrm{CpCo}(\mathrm{CO})_{2} \mathrm{Co}-103$ and $\mathrm{NH}_{3}$ versus $\mathrm{H}_{2}$ plasma; the latter produced Co films with $\mathrm{C}$ contamination, while the former yielded pure $\mathrm{Co}$ at $300^{\circ} \mathrm{C}^{20,51}$

- $\mathrm{Co}(\mathrm{MeCp})_{2}(\mathrm{Co}-204)$ and $\mathrm{CoCp}_{2}(\mathrm{Co}-203)$ were both tested with $\mathrm{NH}_{3}$ versus $\mathrm{H}_{2}$ plasma at $100-350^{\circ} \mathrm{C},{ }^{36}$ with only $\mathrm{NH}_{3}$ plasma depositing Co metal. The investigators concluded that the presence of $\mathrm{NH}_{3}$ radicals is critical to obtain Co metal, which is consistent with other reported results. ${ }^{20,46,51}$

- Dicobalt hexacarbonyl t-butylacetylene (Co-003) in an $\mathrm{H}_{2}$ plasma at $150^{\circ} \mathrm{C}^{41}$

A number of thermal ALD studies investigated the role of coreactants in the adsorption, reaction and decomposition of Co source precursors to yield metallic cobalt. Metallic Co was reported by a number of investigators from the following Co sources:

- $\mathrm{Bis}\left(\mathrm{N}, \mathrm{N}\right.$-diisopropylacetamidinato) $\mathrm{Co}^{(\mathrm{II})}$ (Co-206) with $\mathrm{NH}_{3}$ versus $\mathrm{H}_{2}$ as co-reactants at $300^{\circ} \mathrm{C}$. Co films grown by ALD with $\mathrm{NH}_{3}$ as co-reactant were denser and exhibited 4 times lower resistivity $(\sim 50 \mu \Omega \mathrm{cm})$ than those deposited with $\mathrm{H}_{2}$. This finding appears to be consistent with the results reported by other investigators for PE-ALD using $\mathrm{CoCp}_{2}(\mathrm{Co}-203)$ as Co source precursor. ${ }^{20,65,66}$ 
- Bis(1,4-di-t-butyl-1,3-diazabutadienyl)Co(II) (Co-208) with forming gas as co-reactant at $180^{\circ} \mathrm{C} .^{39}$

Some ALD studies yielded metallic cobalt but in a growth regime that involved a significant MOCVD component. These Co source precursors would therefore qualify for pulsed MOCVD instead:

- $\mathrm{Co}(\mathrm{iPrNCMeNiPr})_{2}(\mathrm{Co}-206)$ with $\mathrm{H}_{2}$ as co-reactant at 300 $350^{\circ} \mathrm{C}$ to yield metallic $\mathrm{Co}$. The substrate temperatures are significantly higher than the precursor decomposition temperature of 215$225^{\circ} \mathrm{C}$, however, indicating a CVD rather than true ALD growth mode. ${ }^{56,57}$

- Carbonyl-based Co complexes: dicobalt octacarbonyl ${ }^{37}$ (Co001) and t-Bu-acetylene) dicobalt hexacarbonyl (Co-003) in $\mathrm{H}_{2}$ plasma. ${ }^{37,60}$ Since CCTBA decomposes at $101^{\circ} \mathrm{C}$ and dicobalt octacarbonyl (Co-001) loses $\mathrm{CO}$ at room temperature, the authors surmised that the growth mechanisms involved a significant CVD component

- $\left[\mathrm{Co}(\mathrm{CO})_{2}(\mathrm{NO})\left({ }^{\mathrm{i}} \mathrm{Pr}_{2} \mathrm{Im}\right)\right] \quad(\mathrm{Co}-109), \quad\left[\mathrm{Co}(\mathrm{CO})(\mathrm{NO})\left({ }^{\mathrm{i}} \mathrm{Pr}_{2} \mathrm{Im}\right)\right.$ $\left.\mathrm{PMe}_{3}\right]$, and $\left[\mathrm{Co}(\mathrm{CO})(\mathrm{NO})\left({ }^{\mathrm{i}} \mathrm{Pr}_{2} \mathrm{Im}\right)\left(\mathrm{PMe}_{3}\right)\right]$ were all explored with $\mathrm{Ar}$ as co-reactant at substrate temperatures in the range $70-175^{\circ} \mathrm{C} .^{44}$ The authors reported that the precursors did not show any self-limiting growth behavior and therefore cannot be used as strictly ALD precursors, but concluded that the precursors are suitable for low-temperature CVD of Co films.

Reports worth noting in light of their unique and innovative approach to the growth of metallic Co include:

- An electrochemical ALD (e-ALD) process that employed a 2step approach based on a $\mathrm{CoSO}_{4}$ electrolyte at a $\mathrm{pH}$ of 6.5. In a first step, underpotential deposition (UPD) is applied to grow a zinc ( $\mathrm{Zn}$ ) seed layer on a ruthenium $(\mathrm{Ru})$ substrate; the sacrificial $\mathrm{Zn}$ layer is then subjected to spontaneous surface-limited redox replacement (SLRR) by Co to yield metallic Co. ${ }^{26}$

- ALD $\mathrm{CoO}$ was obtained from the ALD reaction of $\mathrm{CoCl}_{2}$ (TMEDA) and $\mathrm{H}_{2} \mathrm{O}$ as co-reactant at substrate temperatures in the range $225-300^{\circ} \mathrm{C}$. The $\mathrm{CoO}$ layer was then subjected to a reduction process in $10 \%$ forming gas $\left(\mathrm{H}_{2} / \mathrm{N}_{2}\right)$ to yield Co beginning at temperatures as low as $250^{\circ} \mathrm{C} 4^{42}$

\section{Area-Selective ALD}

Tables VI and IX present a synopsis of area-selective ALD Co applications, processing parameters, post-processing treatments (where applicable) and pertinent findings. A review of Tables VI and IX shows the following common trends in recent area-selective ALD work:

Area-selective ALD Co films are being explored exclusively for conventional and unconventional IC applications. Traditional applications include $\mathrm{CoSi}_{2}$ as contact material in MOS field effect transistors (MOSFET), as well as capping, seed, adhesion and diffusion barrier layers for $\mathrm{Cu}$ in multilevel metallization schemes. Emerging usages exploit cobalt's magnetic dipole moment for incorporation in spintronic and GMR devices and spin valves. The primary benefit of area-selective ALD Co is its potential to eliminate a number of the steps involved in conventional IC patterning and etching technologies, leading to an appreciable increase in manufacturing throughput and a significant reduction in cost of ownership.

Cold-wall thermal ALD processes are the exclusive methods for area-selective cobalt deposition. Due to the critical role that the substrate surface plays in the selective deposition process and the need to tightly control precursor-substrate interactions to enable or prohibit Co deposition on specific areas of the underlying substrate surface, no plasma activation or enhancement of any kind was used. Various cobalt precursors with oxidation states ranging from 1 to 2 were utilized with a substrate temperature in the range of $140-350^{\circ} \mathrm{C}$. Co-reactants included $\mathrm{H}_{2}, \mathrm{NH}_{3},\left(\mathrm{H}_{2}+\mathrm{NH}_{3}\right)$ mixture, dimethylhydrazine (DMHz), tbutylamine, diethylamine, triethylamine and formic acid, while carrier gases were primarily inert-namely argon (Ar) or nitrogen $\left(\mathrm{N}_{2}\right)$. Substrate surface preparation techniques are also critical in area-selective $\mathrm{ALD}$, and included semiconductor [hydrogen-terminated $\mathrm{Si},(\mathrm{H}-\mathrm{Si})$ ], insulator [hydroxyl-terminated $\mathrm{SiO}_{2},\left(\mathrm{OH}-\mathrm{SiO}_{2}\right)$, low-k $(k \sim 2.6)$ dielectric carbon-doped oxide (CDO), octadecyltrichlorosilane (OTS)], and metallic surfaces $(\mathrm{Cu}, \mathrm{Ru}$, and $\mathrm{Pt})$. Noteworthy investigations and associated findings are discussed below.

Lee et al. ${ }^{59}$ performed a two-phase investigation of the ALD adsorption and reaction mechanisms of bis(N,N'diisopropylacetamidinato) $\mathrm{Co}^{\mathrm{II}}$ (Co-206) with either $\mathrm{H}_{2}$ or $\mathrm{NH}_{3}$ as co-reactant at a substrate temperature of $350^{\circ} \mathrm{C}$. In phase I of the study, Co films were successfully deposited on $\mathrm{Si}(001)$ and $\mathrm{SiO}_{2}$ substrates with either $\mathrm{H}_{2}$ or $\mathrm{NH}_{3}$ as co-reactant. However, films grown using $\mathrm{NH}_{3}$ as co-reactant were metallic and pure Co with little to no $\mathrm{N}$ inclusion, while their $\mathrm{H}_{2}$ counterparts exhibited high oxygen levels. This finding is consistent with the reports on the role of $\mathrm{NH}_{3}$ radicals in the clean cleavage of Co precursors discussed in Section 7. ${ }^{20,51}$ In phase II of this study, Co films grown by ALD on patterned octadecyltrichlorosilane (OTS) on $\mathrm{SiO}_{2}$ using either co-reactant formed selectively on $\mathrm{SiO}_{2}$ but not on OTS, indicating that OTS did effectively block the ALD nucleation and growth process.

Kwon et al. ${ }^{60}$ analyzed the thermal ALD reaction of t-butylallylcobalt tricarbonyl (Co-108) with dimethylhydrazine $(\mathrm{DMHz})$ as co-reactant at a substrate temperature of $140^{\circ} \mathrm{C}$ on $\mathrm{OH}-$ terminated $\mathrm{SiO}_{2}$ and $\mathrm{H}$-terminated $\mathrm{Si}(111)$. Unexpectedly, they observed ( $\left.{ }^{\mathrm{t}} \mathrm{Bu}-\mathrm{Allyl} \mathrm{Co}(\mathrm{CO})_{3}\right)(\mathrm{Co}-108)$ to be substantially more reactive with $\mathrm{H}$-terminated $\mathrm{Si}$ than $\mathrm{OH}$-terminated $\mathrm{SiO}_{2}$. The authors also conducted theoretical calculations that indicated significant differences in the surface reaction energies of $\mathrm{Si}$ versus $\mathrm{SiO}_{2}$ - differences which act as the underlying driver for the observed Co source precursor selectivity.

Elko-Hansen et al. ${ }^{61}$ examined area-selectivity in ALD Co using bis(N-t-butyl-N'-ethylpropionamidinato) $\mathrm{Co}^{(\mathrm{II})}$ (CoAMD) (Co209) and $\mathrm{H}_{2}$ as co-reactant at a substrate temperature of $265^{\circ} \mathrm{C}$ on $\mathrm{Cu}, \mathrm{SiO}_{2}$ and porous low-k ( $\left.k \sim 2.6\right) \mathrm{C}$-doped oxide (CDO). Adsorption studies showed that $\mathrm{Co}$ growth occurred most preferentially on $\mathrm{Cu}$ and least preferentially on $\mathrm{CDO}$, and that, similarly to other amidinate precursors, CoAMD (Co-209) readily dissociated on transition metal surfaces such as $\mathrm{Cu}$ via a complex dissociative chemisorption mechanism. The investigation also indicated that the CoAMD per-cycle coverage on $\mathrm{Cu}$ is ALD-like and self-limited by the slow desorption of amidinate ligands and fragments from the $\mathrm{Cu}$ surface. However, significant $\mathrm{Cu}-\mathrm{Co}$ intermixing by $\mathrm{Cu}$ diffusion through grain boundaries in the Co matrix was observed. The Co films also exhibited appreciable $\mathrm{C}$ and $\mathrm{N}$ contamination. Alternatively, the adsorption of CoAMD on $\mathrm{SiO}_{2}$ and $\mathrm{CDO}$ surfaces seemed to be driven by interactions with exposed $\mathrm{OH}$ moieties. Both $\mathrm{SiO}_{2}$ and $\mathrm{CDO}$ favored the formation of oxidized $\mathrm{Co}^{2+}$ and possibly $\mathrm{Co}^{3+}$ species, as well as some partially reacted CoAMD precursor.

One study by Kerrigan et al. ${ }^{63}$ carried out a two-phase investigation of area-selective ALD Co from the reaction of bis(1,4-di-tbutyl-1,3-diazadienyl)cobalt [Co(tBuNCHCHNtBu$\left.)_{2}\right](\mathrm{Co}-208)$ with t-butylamine, diethylamine or triethylamine as co-reactants at a substrate temperature of $200^{\circ} \mathrm{C}$. In phase I, ALD Co growth was observed with t-butylamine or diethylamine as co-reactants on conducting $(\mathrm{Pt}, \mathrm{Ru}$, and $\mathrm{Cu})$ but not on insulating surfaces ( $\mathrm{Si}(100)$ with native oxide, thermal $\mathrm{SiO}_{2}, \mathrm{H}_{2}$ terminated $\mathrm{Si}$ and $\mathrm{C}$-doped oxide (CDO)). No growth was achieved with triethylamine as co-reactant on any surface. The authors attributed this behavior to coordination of the amine $\mathrm{N}$ atom lone pair to the $\mathrm{Co}$ ion to form an adduct consisting of a $\mathrm{Co}^{(\mathrm{II})}$ ion attached to two radical anion diazadienyl ligands. At the deposition temperatures $\left(\geq 160^{\circ} \mathrm{C}\right)$, an electron transfer occurred from the two radical anion diazadienyl ligands to the $\mathrm{Co}^{\text {(II) }}$ ion, causing the formation of Co metal, tert-butylamine and two equivalents of 1,4-di-t-butyl-1,3-diazadiene (Co-208). They further argued that triethylamine does not contain any $\mathrm{N}-\mathrm{H}$ bonds, which may be required to provide a similar role to tert-butylamine and diethylamine. In phase II of this study, the authors performed similar area-selective ALD studies of the reaction of [Co(tBuNCHCHNtBu$\left.)_{2}\right]$ (Co-208) with t-butylamine or diethylamine on patterned substrates consisting of $\mathrm{Si}(100)$ substrates with a single, $1000 \mathrm{~nm}$-wide by $\sim 60$ to $80 \mathrm{~nm}$ thick Pt stripe. After 1000 ALD deposition cycles, Co 
growth was achieved on the Pt stripe but not on the surrounding $\mathrm{Si}$ region.

Another study by Kerrigan et al. ${ }^{64}$ examined area-selective ALD behavior in the reaction of bis(1,4-di-t-butyl-1,3-diazadienyl)cobalt (Co-208) with formic acid at a substrate temperature of $180^{\circ} \mathrm{C}$ on $\mathrm{Pt}$, $\mathrm{Ru}, \mathrm{Cu}, \mathrm{Si}(100)$ with native oxide, thermal $\mathrm{SiO}_{2}, \mathrm{H}_{2}$ terminated $\mathrm{Si}$ and CDO. Normal ALD growth was reported on $\mathrm{Pt}$ and $\mathrm{Cu}$ surfaces even within the first 25 deposition cycles. Alternatively, Co growth was hindered on Ru surfaces for the first 100 cycles, followed by deposition at very low growth rates until 250 cycles, when a higher ALD growth rate was achieved. This behavior indicated a nucleation delay on $\mathrm{Ru}$ until surface treatment with formic acid exposed active surface nucleation sites. Once the Ru substrate was covered with an ultrathin Co layer, typical self-limited ALD growth was observed. No Co deposition was observed on $\mathrm{Si}(100), \mathrm{Si}-\mathrm{H}$ and $\mathrm{CDO}$ substrates, while films grown on thermal $\mathrm{SiO}_{2}$ were non-conductive and lacked the metallic texture of $\mathrm{Co}$. Analyses indicated the formation of $\mathrm{Co}^{\text {(II) }}$ formate on the $\mathrm{SiO}_{2}$ surface.

\section{Overview of Cobalt Source Chemistries}

The differences in the formation and behavior of cobalt thin films can be attributed in part to fundamental thermodynamic and chemical properties of the source precursors. Table $\mathrm{X}$ lists the bond dissociation energies for the indicated bonds in selected cobalt compounds relevant to MOCVD and ALD cobalt. Table XI presents relevant properties of the CVD and ALD cobalt source precursors discussed in this review. The precursors are divided into classes based on the nominal valence (oxidation state) of cobalt. Representative structures of each class are depicted below.

Zero valent cobalt $\left(\mathrm{Co}^{0}\right)$ precursors include cobalt carbonyl compounds such as cobalt carbonyl adducts, dicobalt octacarbonyl, cobalt carbonyl nitrosyl, and cobalt carbonyl t-butylacetylene.

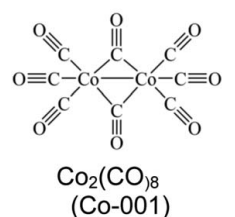

(Co-001)

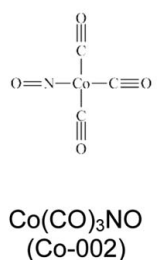

(Co-002)

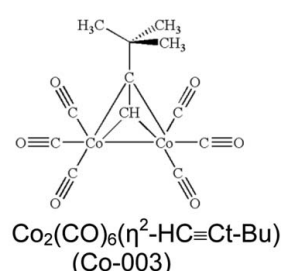

(Co-003)
Monovalent cobalt $\left(\mathrm{Co}^{+1}\right)$ precursors include cobalt carbonyl hydride, and cyclopentadienyl cobalt dicarbonyl.
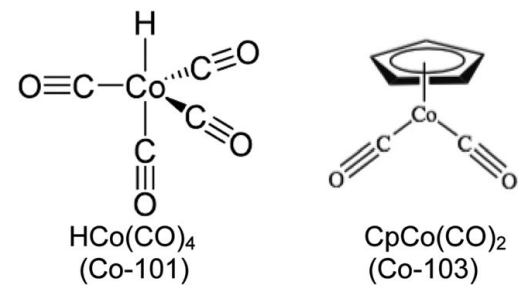

Divalent cobalt $\left(\mathrm{Co}^{+2}\right)$ precursors include cobalt diketonates, cobaltocenes, and cobalt amidinates.

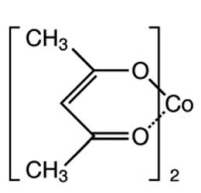

$\mathrm{Co}(\mathrm{acac})_{2}$ (Co-201)

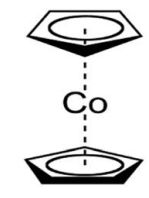

$\mathrm{CoCp}_{2}$

(Co-203)

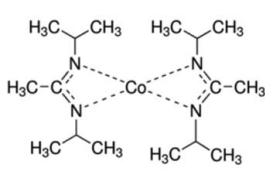

$\mathrm{Co}(\mathrm{i}-\mathrm{Pr}-\mathrm{AMD})_{2}$ (Co-206)
Trivalent cobalt $\left(\mathrm{Co}^{3+}\right)$ precursors include oxidation state 3 , as well as mixtures of oxidation states 2 and 3 , such as:

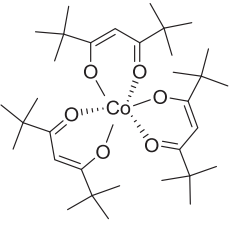

301

$\mathrm{Co}(\mathrm{TMHD})_{3}$

(Co-301)

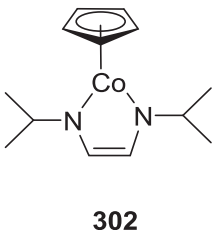

$\mathrm{CpCo}\left(\mathrm{i}-\mathrm{Pr}_{2} \mathrm{dab}\right)$

(C-302)
While, in general, the requirement that desirable precursors for CVD and ALD needs to be volatile, stable during storage and transport, and preferably gas or liquid, in the case of cobalt deposition, it should be recognized that many of cobalt precursors are dinuclear (2 cobalt atoms) solids with relatively low volatility. Further, dinuclear complexes are often subject to gas phase nucleation reactions at high vapor pressures and higher temperatures $\left(>200^{\circ} \mathrm{C}\right)$.

The performance of cobalt source chemistries for vapor deposition techniques can be most readily anticipated by considering not only the primary cobalt precursor, but the type of co-reactant used, the structure and composition of the substrate surface, and whether the desired film is in a zero oxidation state (cobalt metal or alloys) or a higher oxidation state (cobalt oxides or sulfides).

$\mathrm{Co}^{0}$ precursors, the most widely used sources for generating metallic cobalt films, are coordination complexes bearing labile ligands. The success of this class of precursors at depositing pure metallic Co by MOCVD was reported as early as 1999 by Ivanova et al., ${ }^{3}$ using the source precursor cobalt tricarbonyl nitrosyl (Co-002). This success can be simplistically associated with the low bond dissociation energies of the ligands $(<100 \mathrm{~kJ} / \mathrm{mole})$ as well as the fact that no formal reduction of the cobalt species is required. Under thermal deposition conditions - namely, non-plasma or radical-induced reactionsprecursor behavior during deposition is generally sensitive to carrier gas and substrate surface composition: both the surface interaction of nominally neutral ligands displaced from $\mathrm{Co}^{0}$ precursor complexes with the substrate and the mechanisms for the release or elimination of the ligands from the substrate appear to play an important role in film formation.

While deposition of metals is associated with reducing conditions in most cases, mildly oxidative co-reactants are frequently employed that can selectively react with the ligands.

For example, it appears that a carbonyl ligand (CO) can be released from the adsorbed complex by: (i) conversion to carbon dioxide $\left(\mathrm{CO}_{2}\right)$ via reaction with oxygen, (ii) conversion to formaldehyde $\left(\mathrm{H}_{2} \mathrm{CO}\right)$ by reaction with hydrogen, or (iii) conversion to formamide $\left(\mathrm{HCONH}_{2}\right)$ by reaction with ammonia. While it is difficult to quantify, cobalt deposition appears to be more sensitive to substrate surface composition and structure than other metal deposition schemes. A recent observation is that some of the $\mathrm{Co}^{0}$ precursors such as CCTBA (Co-003) undergo exothertic decomposition at temperature below $200^{\circ} \mathrm{C}$ while others undergo endothermic decomposition. ${ }^{105}$

Deposition on oxides appears to be profoundly different than deposition on metallic substrates, presumably due to differences between the surface electron density of non-metallic and metallic substrates. Copper, for instance, is a far better substrate for metallic cobalt deposition than silicon dioxide. Silicon substrates rich in hydrogen exhibit area specific cobalt deposition, while deposition onto oxidized, hydroxyl containing substrates is suppressed. ${ }^{60}$ Substrates with an affinity for the co-reactants-particularly oxides — can contribute mechanistic pathways for release of the ligands in the deposition of nonmetallic cobalt films. It should also be noted that bulk cobalt metal undergoes a transition from hcp to fcc crystalline form at $>400^{\circ} \mathrm{C}$, ${ }^{68}$ undoubtedly altering the sticking coefficient and adsorption mechanisms of both the precursor and deposition byproducts. 


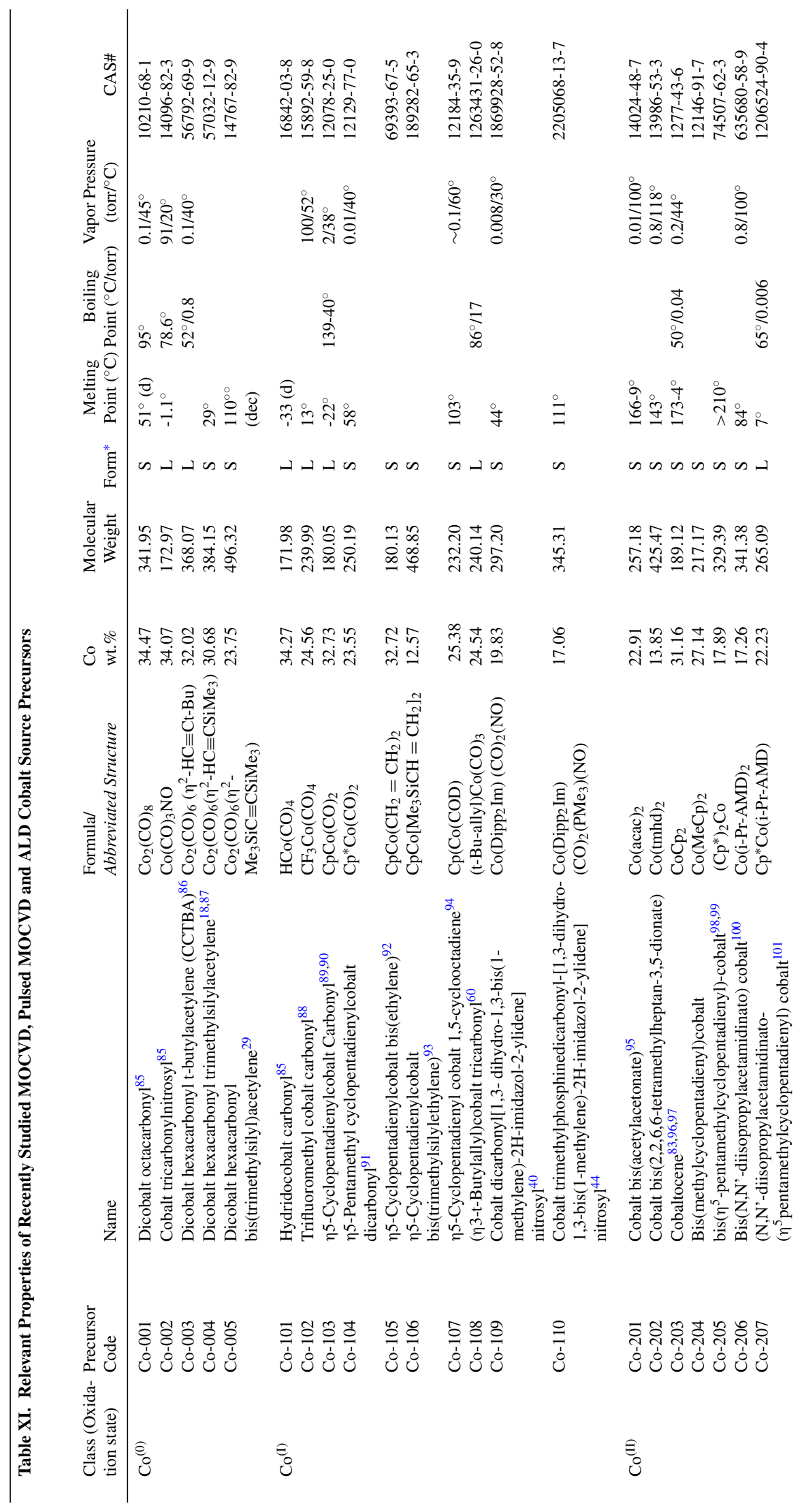




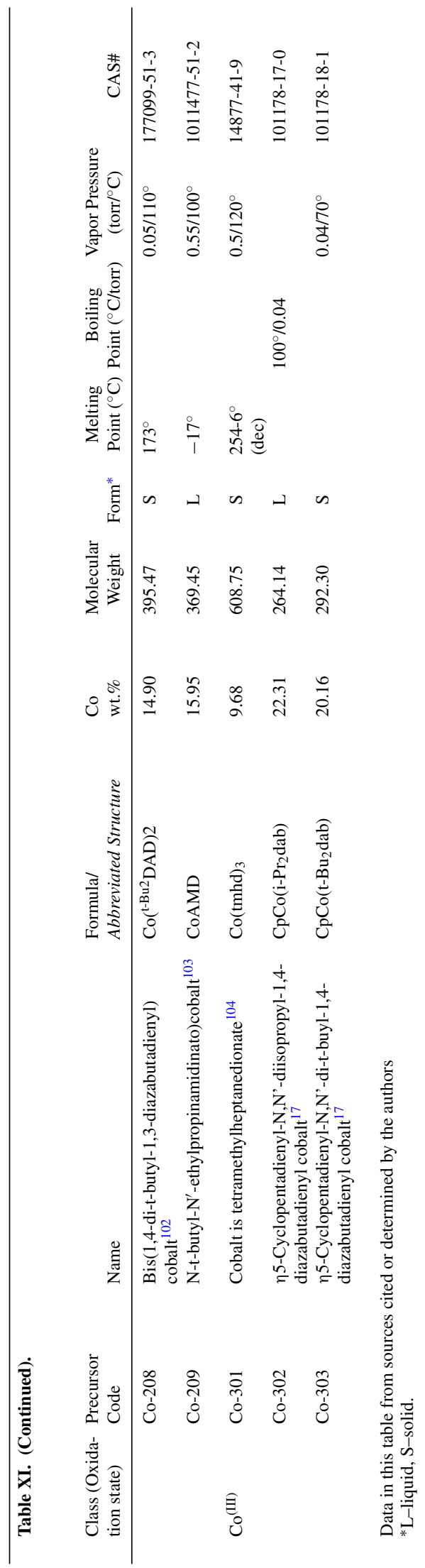


A comparison of the generation of metallic cobalt by thermal MOCVD and ALD using $\mathrm{Co}^{0}$ precursors versus $\mathrm{Co}^{2+}$ precursors reveals some general trends: in order to yield metallic Co with $\mathrm{Co}^{2+}$ precursors, there seems to be a need for higher substrate temperatures with precisely selected co-reactants, and/or specifically customized substrate surface structure and composition in a narrower process window than when using $\mathrm{Co}^{0}$ precursors. For example, $\mathrm{Co}(\mathrm{acac})_{2}$ (Co-201) dissolved in n-propanol solution yielded metallic Co on $\mathrm{Ni}$ at substrate temperatures above $250^{\circ} \mathrm{C}$, but yielded cobalt carbide when dissolved in isopropanol. ${ }^{8}$ Similarly, Co $\left({ }^{\mathrm{i}} \mathrm{Pr}-\mathrm{MeAMD}\right)_{2}(\mathrm{Co}-$ 206) dissolved in tetradecane produced metallic cobalt only with a $\mathrm{NH}_{3} / \mathrm{H}_{2}$ ratio of 1 at a substrate temperature of $240^{\circ} \mathrm{C} ; \mathrm{H}_{2}$ alone failed to generate any deposition, while $\mathrm{NH}_{3}$ alone yielded hcp $\mathrm{Co}_{3} \mathrm{~N}^{32}$ Another general trend is that deposition protocols with added energy sources such as PE-CVD or PE-ALD offer little to no benefit for the deposition of high purity, low resistivity metallic cobalt films due to the fact that other, non-cobalt elemental contaminants are incorporated into the film.

Cobalt precursors in non-zero oxidation states are often preferred for the deposition of non-metallic cobalt films including sulfides, oxides and non-stoichiometric nitrides. While it is appealing to assume that a ligand or adduct bearing an atom of interest could form a binary cobalt compound-e.g., a diketonate contributing an oxygen atom to form a cobalt oxide or an amidinate contributing a nitrogen atom to form cobalt nitride - no instances of a single source precursor yielding a targeted film stoichiometry have been reported. As deposition pathways vary widely and the decomposition of the ligands is not straightforward, a co-reactant is required.

This situation is further complicated by the fact that the substrate surface is evolving during the growth process, starting with the initial substrate but transitioning to a cobalt containing surface as a film grows. ${ }^{10}$ Yao provides an example of this complexity for amidinates: decomposition of the pyrrolidinate ligand leads to the desorption of several gas-phase products including $\mathrm{CH}_{3} \mathrm{CN}, \mathrm{HCN}$ and butene from the metals, as well as $\mathrm{CO}$ and $\mathrm{CO}_{2}$ from the oxygen-containing surfaces; in all cases, dehydrogenation of the organic moieties is accompanied by hydrogen removal, mainly in the form of $\mathrm{H}_{2}$ from metallic surfaces and as water from metal oxide surfaces; however, the threshold for this reaction varies wildly: from $270 \mathrm{~K}$ on $\mathrm{Ni}(110)$ to $430 \mathrm{~K}$ on $\mathrm{O} / \mathrm{Cu}(110), 470 \mathrm{~K}$ on $\mathrm{Cu}(110), 500 \mathrm{~K}$ on $\mathrm{NiO} / \mathrm{Ni}(110)$ and $570 \mathrm{~K}$ on $\mathrm{SiO}_{2} / \mathrm{Ta}$.

Cyclopentadienyl ligands (Cp) almost always are problematic. While this class of compounds has excellent storage and transport properties, the high energy barriers for homolytic bond dissociation for cobaltocenes (dicyclopentadienylcobalt compounds; CpCo-Cp (Co203): $341.6 \mathrm{~kJ} / \mathrm{mol}$ ) almost always exhibit alternate decomposition pathways that result in the incorporation of carbon. ${ }^{51}$

The performance of $\mathrm{Co}^{\circ}$ compounds remains the most advantageous for thermally-induced metallization schemes. However, the advantage of $\mathrm{Co}^{0}$ compounds is mitigated the introduction of plasma causes precursor decomposition by ionization prior to neutral compound bond dissociation. In higher valent cobalt binary thin films such as cobalt oxides and sulfides, ionizing methods are more likely to generate acceptable film qualities. Alternatively, $\mathrm{Co}^{0}$ precursors are less likely to produce optimum properties for binary films due to gas phase depletion reactions initiated in the ionizing environments.

\section{Summary and Commentary}

This article has reviewed the most recent published work on MOCVD, plasma and thermal ALD, and pulsed MOCVD Co technologies, with an emphasis on important new advances in Co thin film systems focused on Co source precursors, mechanistic and modeling studies, transport and delivery techniques, thin film growth processes, and their resulting effects on film properties. Innovative approaches to Co deposition were also discussed, including electrochemical ALD (e-ALD), area-selective ALD and two-step processes for the formation of metallic Co. The volume of work examined indicates that Co is the target of an expanding body of research and development
(R\&D) efforts, especially as it enters main stream IC manufacturing technologies.

While generalizations are difficult when such a wide range of Co oxidation states, chemistries and applications are considered, some common trends can be identified from a chemistry perspective. Although exceptions exist, the most general, fully anticipated trend is that metallic cobalt films are more readily deposited using lower oxidation state cobalt precursors- $\mathrm{Co}^{0}$ in particular-and that higher oxidation state cobalt precursors are generally more amenable to the formation of binary cobalt compound films. Departures from this simple paradigm are generally associated with strategies that involve substrate interaction, film thickness and conformality requirements.

From a processing perspective, the evolution in Co deposition methodology generally mirrors that of many other material systems as the technological drive continues toward sub-nanometer scale devices and structures. The latter require exact atomic level control of the composition, uniformity and morphology of exceedingly thin Co layers, down to a thickness of a few atoms. As a result, Co deposition techniques have gradually migrated from traditional MOCVD to ALD processes in light of the need for exceedingly thin cobalt films which must be deposited uniformly, continuously and coherently. ${ }^{69}$ As a rather simplistic example of this need, a $2 \mathrm{~nm}$-thick Co film will consist of a layer only $\sim 15$ atoms thick; while MOCVD produces inherently poor step coverage due to device structures becoming substantially more complex, with higher aspect ratio and narrower channels, vias and trenches, ALD has the intrinsic capacity to offer precise atomic level control and exceptional conformality for cobalt ultrathin films in nanoscale IC device structures.

Finally, two additional trends in Co deposition techniques are also worth noting. The first is area-specific or area-selective Co thermal ALD, which is characterized by the ability to catalyze or prevent Co deposition on specific areas of the substrate: specifically-designed Co source precursors are made to interact preferentially with pre-treated substrate surface patterns and geometries to yield Co films only on the targeted regions of the substrate surface. The second is pulsed MOCVD, wherein the co-reactants get pulsed simultaneously into the reaction zone, thus providing the potential to combine the advantages of both MOCVD and ALD. Both trends are still in their infancy, and significant future R\&D efforts will be required to assess their manufacturability. Concurrently, the field of Co deposition methods is expected to benefit from the introduction of new atomic and molecular level surface treatment and film deposition protocols such as Molecular Layer deposition (MLD) and self-assembled monolayers (SAMs).

\section{ORCID}

Barry Arkles 느 https://orcid.org/0000-0003-4580-2579

\section{References}

1. A. Kafizas, C. J. Carmalt, and I. P. Parkin, Coord. Chem. Rev., 257, 2073 (2013).

2. Y. Nakamura, in ECS Transactions, 3, 29, ECS (2007).

3. A. R. Ivanova et al., J. Electrochem. Soc., 146, 2139 (1999).

4. A. E. Kaloyeros, A. Londergan, and B. Arkles, US Pat. 6,346,477 (2002).

5. F. Zaera, Coord. Chem. Rev., 257, 3177 (2013).

6. D. J. H. Emslie, P. Chadha, and J. S. Price, Coord. Chem. Rev., 257, 3282 (2013).

7. S. D. Elliott, G. Dey, and Y. Maimaiti, J. Chem. Phys., 146, 052822 (2017).

8. P. A. Premkumar, A. Turchanin, and N. Bahlawane, Chem. Mater, 19, 6206 (2007).

9. N. D. Papadopoulos, E. Illekova, H. S. Karayanni, and E. Hristoforou, J. Optoelectron. Adv. Mater, 10, 1098 (2008)

10. K. Lee et al., Jpn. J. Appl. Phys., 47, 5396 (2008).

11. D. Lammers, Semicond. Manuf. Des. Community, (2017) semimd.com/ blog/2017/12/21.

12. P. Singer, Semicond. Des. Manuf. Community, (2018) http://semimd.com/blog/ tag/cobalt/.

13. A. R. Londergan et al., J. Electrochem. Soc., 148, C21 (2001).

14. S. I. Dorovskikh et al., Surf. Eng., 32, 8 (2016).

15. N. Samal, K. B. Chetry, K. Rook, A. Hayes, and A. Devasahayam, J. Vac. Sci. Tech nol. B, Nanotechnol. Microelectron. Mater. Process. Meas. Phenom., 32, 011206 $1-5$ (2014). 
16. J. A. Hamilton, T. Pugh, A. L. Johnson, A. J. Kingsley, and S. P. Richards, Inorg. Chem., 55, 7141 (2016).

17. T. Pugh, S. D. Cosham, J. A. Hamilton, A. J. Kingsley, and A. L. Johnson, Inorg. Chem., 52, 13719 (2013).

18. C. Georgi, A. Hildebrandt, A. Tuchscherer, S. Oswald, and H. Lang, Zeitschrift fur Anorg. und Allg. Chemie, 639, 2532 (2013).

19. C. Georgi et al., Thin Solid Films, 578, 180 (2015).

20. B. K. Ramos, M. J. Saly, and Y. J. Chabal, Coord. Chem. Rev., 257, 3271 (2013).

21. A. C. Frank and P. T. A. Sumodjo, Electrochim. Acta, 132, 75 (2014).

22. C. Q. Cui, S. P. Jiang, and A. C. C. Tseung, J. Electrochem. Soc., (1990).

23. K. Nakaoka, M. Nakayama, and K. Ogura, J. Electrochem. Soc., (2002).

24. Q. Huang, T. W. Lyons, and W. D. Sides, J. Electrochem. Soc., (2016).

25. M. R. Khelladi, L. Mentar, M. Boubatra, A. Azizi, and A. Kahoul, Mater. Chem Phys., 122, 449 (2010).

26. K. Venkatraman, Y. Dordi, and R. Akolkar, J. Electrochem. Soc., 164, D104 (2017).

27. E. A. Owen and D. M. Jones, Proc. Phys. Soc. Sect. B, 67, 456 (1954).

28. D. H. Buckley and L. Johnson Robert, NASA Tech. Note, TN D-2523 (1964)

29. C. Georgi et al., J. Mater. Chem. C, 2, 4676 (2014).

30. K. Shima, H. Shimizu, T. Momose, and Y. Shimogaki, ECS J. Solid State Lett., 3, P20 (2014)

31. T. Weiss, V. Zielasek, and M. Bäumer, Sci. Rep., 5, 18194 (2015).

32. J. Yang, K. Li, J. Feng, and R. G. Gordon, J. Mater. Chem. C, 3, 12098 (2015).

33. Y. Zhang, L. Du, X. Liu, and Y. Ding, New J. Chem., 42, 9110 (2018).

34. H. Shimizu, K. Sakoda, and Y. Shimogaki, Microelectron. Eng., 106, 91 (2013).

35. M. C. Karunarathne, T. J. Knisley, G. S. Tunstull, M. J. Heeg, and C. H. Winter, Polyhedron, 52, 820 (2013)

36. J. Park et al., J. Energy Chem., 22, 403 (2013).

37. J. H. Park et al., Surf. Coatings Technol., 259, 98 (2014).

38. T. D. M. Elko-Hansen, A. Dolocan, and J. G. Ekerdt, J. Phys. Chem. Lett., 5, 1091 (2014).

39. J. P. Klesko, M. M. Kerrigan, and C. H. Winter, Chem. Mater, 28, 700 (2016).

40. F. Hering et al., Organometallics, 35, 2806 (2016).

41. J. You and Y. Guo, J. Alloys Compd., 758, 116 (2018).

42. K. Väyrynen et al., Chem. Mater, 30, 3499 (2018).

43. T. Nam et al., J. Alloys Compd., 737, 684 (2018).

44. K. Lubitz et al., Organometallics, 37, 1181 (2018).

45. K. B. Klepper, O. Nilsen, and H. Fjellvåg, Thin Solid Films, (2007).

46. M. F. J. Vos, G. van Straaten, W. M. M. E. Kessels, and A. J. M. Mackus, J. Phys. Chem. C, 122, 22519 (2018).

47. S. T. Barry, A. V Teplyakov, and F. Zaera, Acc. Chem. Res., 51, 800 (2018).

48. M. Diskus, O. Nilsen, and H. Fjellvåg, Chem. Vap. Depos., 17, 135 (2011).

49. E. Rauwel et al., Chem. Vap. Depos., 18, 315 (2012).

50. B. Han, K. H. Choi, K. Park, W. S. Han, and W.-J. Lee, Electrochem. Solid-State Lett., 15, D14 (2011).

51. J. Yoon et al., J. Electrochem. Soc., 158, H1179 (2011)

52. L. C. Kalutarage, P. D. Martin, M. J. Heeg, and C. H. Winter, J. Am. Chem. Soc., 135, 12588 (2013).

53. L. C. Kalutarage, P. D. Martin, M. J. Heeg, and C. H. Winter, Inorg. Chem., 52, 5385 (2013).

54. T. J. Knisley, L. C. Kalutarage, and C. H. Winter, Coord. Chem. Rev., 257, 3222 (2013).

55. J. M. Kim et al., Jpn. J. Appl. Phys., 49, 5S2 (2010).

56. B. S. Lim, A. Rahtu, and R. G. Gordon, Nat. Mater, (2003).

57. H.-B.-R. Lee and H. Kim, ECS Trans., 16, 219 (2008).

58. K. Kim et al., Jpn. J. Appl. Phys., 46, L173 (2007)

59. H.-B.-R. Lee et al., J. Electrochem. Soc., 157, D10 (2010).

60. J. Kwon, M. Saly, M. D. Halls, R. K. Kanjolia, and Y. J. Chabal, Chem. Mater, 24, 1025 (2012).

61. T. D. Elko-hansen, Chem. Mater, 26, 2642 (2014).

62. S. D. Elliott et al., Adv. Mater, 28, 5367 (2016).

63. M. M. Kerrigan, J. P. Klesko, and C. H. Winter, Chem. Mater, 29, 7458 (2017)
64. M. M. Kerrigan et al., J. Chem. Phys., 146, 052813 (2017).

65. H.-B.-R. Lee and H. Kim, Electrochem. Solid-State Lett., 9, G323 (2006).

66. K. Hyungjun et al., J. Korean Phys. Soc. (2010).

67. S. Pasko, L. G. Hubert-Pfalzgraf, A. Abrutis, and J. Vaissermann, Polyhedron, 23 735 (2004).

68. F. G. Hodge, Kirk-Othmer Encycl. Chem. Technol., Editor M. H. Kroschwitz, 6, 760 (1993).

69. E. Ahvenniemi et al., J. Vac. Sci. Technol. A, 35, 10801 (2017).

70. G. Govindasamy, P. Murugasen, and S. Sagadevan, Mater. Res., 20, 60 (2017).

71. A. S. Andreev, J. B. D’Espinose De Lacaillerie, O. B. Lapina, and A. Gerashenko, Phys. Chem. Chem. Phys., 17, 14598 (2015).

72. N. Kumar, N. Raman, and A. Sundaresan, Zeitschrift fur Anorg. und Allg. Chemie (2014).

73. K. V. Rao and A. Smakula, J. Appl. Phys. (1965).

74. L. D. Kadam and P. S. Patil, Thickness-dependent properties of sprayed cobalt oxide thin films, p. 225, (2001).

75. S. Schmid, R. Hausbrand, and W. Jaegermann, Thin Solid Films, 567, 8 (2014).

76. J. Dean, Lange's Handbook of Chemistry, 15th ed., McGraw-Hill Inc., (1999).

77. R. Walsh, in Silicon Compounds: Silanes and Silicones, B. C. Arkles and G. L. Larson, Editors, p. 200, Gelest (2008).

78. C.-C. Ye, L.-F. Xie, and X.-H. Ju, Phosphorus. Sulfur. Silicon Relat. Elem., 186, 1948 (2011).

79. Y. R. Luo, Comprehensive Handbook of Chemical Bond Energies, 1st ed., CRC Press, (2007).

80. X. Gong, Q. S. Li, Y. Xie, R. B. King, and H. F. Schaefer, New J. Chem. (2009).

81. B. Sztáray, L. Szepes, and T. Baer, J. Phys. Chem. A (2003).

82. D. B. Jacobson and B. S. Freiser, J. Am. Chem. Soc., 107, 7399 (1985).

83. J. Opitz, Electron impact ionization of cobalt-tricarbonyl-nitrosyl, cyclopentadienylcobalt-dicarbonyl and biscyclopentadienyl-cobalt: appearance energies, bond energies and enthalpies of formation, p. 115, (2003).

84. C. A. Cooper, S. Ivanov, and M.-S. Kim, (2018).

85. P. Gilmont, A. A. Blanchard, C. M. Mason, and R. L. Barnard, in Inorganic Syntheses, (2007).

86. P. Galow, A. Sebald, and B. Wrackmeyer, J. Organomet. Chem. (1983).

87. N. E. Schore, Organic Reactions, Wiley, Hoboken, (1991).

88. W. Hieber, W. Beck, and E. Linder, Zeitschrift für Naturforsch., 16b, 229 (1961).

89. E. O. Fischer and H. Leipfinger, Zeitschrift für Naturforsch., 10b, 353 (1955).

90. T. S. Piper, F. A. Cotton, and G. Wilkinson, J. Inorg. Nucl. Chem. (1955).

91. S. A. Frith, J. L. Spencer, W. E. Geiger Jr., and J. Edwin, Inorg. Synth. (1985)

92. K. Jonas, Angewentde Chemie Suppl., 1005 (1983).

93. M. Hapke, N. Weding, and A. Spannenberg, Organometallics, 29, 4298 (2010).

94. R. B. King, P. M. Treichel, and F. G. A. Stone, J. Am. Chem. Soc., 83, 3593 (1961).

95. J. B. Ellern, R. O. Ragsdale, R. J. Allen, A. B. Chatterjee, and D. F. Martin, Inorg Synth. (1968).

96. E. O. Fischer and R. Jira, Zeitschrift für Naturforsch., 8b, 327 (1953).

97. L. A. Torres-Gómez, G. Barreiro-Rodríguez, and F. Méndez-Ruíz, Thermochim. Acta (1988).

98. U. Kölle and F. Khouzami, Angew. Chemie, 92, 658 (1980).

99. J. L. Robbins, N. Edelstein, B. Spencer, and J. C. Smart, J. Am. Chem. Soc., 104 1882 (1982).

100. B. S. Lim, A. Rahtu, J.-S. Park, and R. G. Gordon, Inorg. Chem., 42, 7951 (2003).

101. C. Lansalot-Matras, C. Dussarat, V. Omarjee, and C. Hsiao, U. S. Pat. 8,349,738 (2013).

102. T. J. Knisley, M. J. Saly, M. J. Heeg, J. L. Roberts, and C. H. Winter, Organometallics, 30, 5010 (2011)

103. D. V. Shenai, M. Bierman, R. DiCarlo, and G. Doherty, and , in ALD Conference 2014, Kyoto (2014)

104. M. A. Siddiqi, R. A. Siddiqui, and B. Atakan, Surf. Coatings Technol. (2007).

105. A. Cooper, V. lvanov, and M. Kim, U. S. Pat. Appl. 2018/0B74738, (2018). 